\title{
Study of n-butanol conversion to butenes: effect of Si/Al ratio on activity, selectivity and kinetics
}

\author{
Dieter Gunst ${ }^{1,2}$, Maarten Sabbe ${ }^{1,2}$, Marie-Françoise Reyniers ${ }^{2}$, An Verberckmoes $^{1 *}$. \\ ${ }^{1}$ Industrial Catalysis and Adsorption Technology (INCAT), Department of Chemical Engineering and Technical \\ Chemistry, Ghent University, Valentin Vaerwyckweg 1, 9000 Ghent, Belgium.
}

${ }^{2}$ Laboratory for Chemical Technology (LCT), Department of Chemical Engineering and Technical Chemistry, Ghent University, Technologiepark 914, 9052 Ghent, Belgium.

\begin{abstract}
:
As bio-butanol is gaining more and more interest as a commercially available bioresource, the dehydration of this alcohol towards butenes and higher carbons gains more of interest. In general HZSM-5 has shown to be the most promising catalyst for this conversion. The role of the zeolite's Si/Al ratio in the butanol dehydration reaction is still not fully understood. Experimental data obtained for a series of HZSM-5 with decreasing Si/Al ratio revealed an increase in activity of the catalyst per active site without affecting the selectivity profile. To understand the underlying effects, a microkinetic model was constructed for H-ZSM-5 with a Si/Al ratio of 25 , based on literature DFT calculations, and the model was further modified by fitting the key parameters to the measured data at the four different temperatures studied in this work. This resulted in an adequate model for the dehydration of butanol across the evaluated temperature range of 503K to 533K. Investigation of the occurring mechanisms indicated a inhibiting effect due to the strong adsorption of di-n-butylether. This 'poisoning' of the catalyst surface resulted in a peculiar S-like curve for the conversion site time relation, which was also experimentally observed. This newly fitted base model was used to obtain more insight in the effect of the Si/Al ratio by implementing an additional $\Delta \Delta \mathrm{H}$ parameter, which is related to the adsorption strength of $\mathrm{n}$-butanol in the base model. $\Delta \Delta \mathrm{H}$ varies between -4.8 to +11.3 $\mathrm{kJ} / \mathrm{mol}$ and provides a good fit for Si/Al ratios ranging from 15 to 140 . The higher dehydration rates observed with decreasing Si/Al can be traced back to an increase in adsorption strength resulting in an overall increase in surface coverage. The constant selectivity-conversion profile can be explained by a similar dependency of all elementary steps on the adsorption strength. The model developed in this study enables to simulate and understand the experimentally observed effects of temperature and $\mathrm{Si} / \mathrm{Al}$ ratio on the $\mathrm{n}$-butanol dehydration.
\end{abstract}

\section{Keywords: HZSM-5, 1-butanol, dehydration, bio-butenes}

\footnotetext{
*Corresponding author: AnVerberckmoes, E-mail address: an.verberckmoes@ugent.be
} 


\begin{tabular}{|c|c|}
\hline \multicolumn{2}{|l|}{ Nomenclature } \\
\hline WHSV & Weight Hourly Space Velocity $\left(\mathrm{hr}^{-1}\right)$ \\
\hline $\mathrm{Si} / \mathrm{Al}$ & Silicon to aluminum ratio \\
\hline $\mathrm{C}$ & Concentration $\left(\mathrm{mol} \mathrm{kg}^{-1}\right)$ \\
\hline A & Area $\left(\mathrm{m}^{2} \mathrm{~g}^{-1}\right)$ \\
\hline $\mathrm{V}$ & Pore volume $\left(\mathrm{m}^{3} \mathrm{~g}^{-1}\right)$ \\
\hline$E_{d}$ & Ammonia desorption energy $\left(\mathrm{kJ} \mathrm{mol}^{-1}\right)$ \\
\hline $\mathrm{E}_{\mathrm{a}}$ & Activation energy $\left(\mathrm{kJ} \mathrm{mol}^{-1}\right)$ \\
\hline$\beta$ & Heating rate $\left(\mathrm{K} \mathrm{min}^{-1}\right)$ \\
\hline $\mathrm{T}_{\mathrm{M}}$ & Peak temperature of ammonia desorption at active site (K) \\
\hline $\mathrm{R}$ & Universal gas constant $\left(\mathrm{J} \mathrm{mol}^{-1} \mathrm{~K}^{-1}\right)$ \\
\hline$\left(\mathrm{W} . \mathrm{C}_{\mathrm{a}}\right) / \mathrm{F}_{\mathrm{BuOH}}$ & Site time ( $\mathrm{mol} \mathrm{s} \mathrm{mol}_{\text {sites }^{-1}}$ ) \\
\hline$X_{i}$ & Conversion of component i $\left(\mathrm{mol} \mathrm{mol}^{-1}\right)$ \\
\hline $\mathrm{S}_{\mathrm{i}}$ & Selectivity towards component i $\left(\mathrm{mol} \mathrm{mol}^{-1}\right)$ \\
\hline $\mathrm{F}_{\mathrm{i}}$ & Molar flowrate of component i $\left(\mathrm{mol} \mathrm{s}^{-1}\right)$ \\
\hline $\mathrm{S}_{\mathrm{i}}$ & Carbon selectivity toward component i $\left(\mathrm{mol} \mathrm{mol}^{-1}\right)$ \\
\hline$b_{i}$ & Number of carbons of component $\mathrm{i}$ \\
\hline $\mathrm{yi}_{\mathrm{i}}$ & Gas phase molar fraction of component i $\left(\mathrm{mol} \mathrm{mol}^{-1}\right)$ \\
\hline $\mathrm{Pi}$ & Partial pressure of component i ( $\mathrm{kPa})$ \\
\hline$\theta$ & Coverages \\
\hline $\mathrm{T}_{\mathrm{av}}$ & Average Temperature of fitted experimental datasets (K) \\
\hline $\mathrm{kb}_{\mathrm{b}}$ & Boltzmann Constant $\left(1,38 \times 10^{-23} \mathrm{~J} \mathrm{~K}^{-1}\right)$ \\
\hline $\mathrm{h}$ & Plancks' Constant $\left(6,63 \times 10^{-34} \mathrm{~m}^{2} \mathrm{~kg} \mathrm{~s}^{-1}\right)$ \\
\hline$A_{f}$ & Activation Energy of foward reaction step \\
\hline $\mathrm{G}_{\mathrm{n}}^{0}$ & Standard-state molar free energy for transition state $n\left(\mathrm{~kJ} \mathrm{~mol}^{-1}\right)$ \\
\hline \multicolumn{2}{|l|}{ Subscripts } \\
\hline f & Forward reaction \\
\hline $\mathrm{i}$ & Component i \\
\hline j & Elementary step number $\mathrm{j}$ \\
\hline k & Surface species k \\
\hline I & Experiment number I \\
\hline $\mathrm{n}$ & Transition state number $\mathrm{n}$ \\
\hline a & Active sites \\
\hline tot & Total \\
\hline ext & External \\
\hline int & Internal \\
\hline micro & Micropore (<2 nm) \\
\hline macro & Macropore (> $50 \mathrm{~nm})$ \\
\hline $\mathrm{BuOH}$ & Butanol \\
\hline \multicolumn{2}{|l|}{ Superscripts } \\
\hline 0 & Inlet \\
\hline M & Model predicted value \\
\hline$\ddagger$ & Transition state \\
\hline \multicolumn{2}{|l|}{ Abbreviations } \\
\hline HZSM-5 & Hydrogen-Zeolite Socony Mobil-5 \\
\hline ABE & Aceton - Butanol - Ethanol fermentation \\
\hline NNN & Next Nearest Neighbor principle \\
\hline ICP-OES & Inductive Coupled Plasma - Optical Emission Spectrometry \\
\hline BET & Brunauer-Emmett-Teller \\
\hline SEM & Scanning Electron Microscopy \\
\hline $\mathrm{NH}_{3}-\mathrm{TPD}$ & Ammonia Temperature Programmed Desorption \\
\hline TCD & Thermal Conductivity Detector \\
\hline PONA & Paraffin's Olefins Naphthenes and Aromatics GC column \\
\hline TOS & Time on Stream \\
\hline TOF & Turn-Over Frequency \\
\hline
\end{tabular}


To ensure a sustainable future, the commercial implementation of biofuel production is gaining substantial interest [1-5]. Different generations of biofuels have been introduced with bio-ethanol being one of the key molecules from the first generation [6-9]. It is easily produced and shows a large potential, but has nevertheless some important drawbacks. It is not ideal for direct implementation in the current technology due to low energy content and complex logistics upon blending, transport and use $[10,11]$. To overcome these drawbacks $n$-butanol has been proposed as a more practical bio-fuel $[11,12]$. Production of this bio-based butanol from renewable biomass can be achieved by different methods such as pyrolysis of biomass [13], the utilization of the lignocellulose waste streams [9] or the Acetone-Butanol-Ethanol (ABE) fermentation process of starches and sugars $[14,15]$ The latter is the most commonly used method for the production of 'green butanol', and it was already commonly used during the 1980's [16-18]. Due to the promising properties of bio-butanol as a fuel additive as such the optimization and commercialization of this process towards butanol has gained a lot of interest [15].

This increased availability of bio-butanol [12] makes it worthwhile to investigate chemical platforms based on bio-butanol. One promising route is the zeolite-catalyzed dehydration of butanol towards butenes [19-24] as a feedstock for specialty chemicals and commodity polymers. Zeolites are widely used as strong acid catalysts. A whole series of zeolite lattices is known, each with their own unique structure often leading to differences in selectivity with a change of zeolite lattice for a specific type of reaction [22, 25-27]. These catalysts have shown to be suitable for the acid-catalyzed dehydration of ethanol and butanol [4, 28-31]. Prior work suggests the same reaction mechanism holds for a range of acidic zeolites on the dehydration of alcohols. This could open the possibility to construct a single micro-kinetic model enabling the description of the catalytic performance of a range of zeolites[32].

The difference in selectivity and activity of the various zeolites is proposed to be related to a change in dominant surface species and pathways, rather than a change in reaction mechanism. These effects on selectivity and activity are caused by a different interaction of the lattice with the formed intermediates and surface species, which can be related to Gibbs free energies of intermediates and/or transition states considered in the micro-kinetic model [32]. The general reaction scheme for 1-butanol dehydration (Figure 1) is assumed to be a parallel-consecutive pathway consisting of the direct dehydration of 1-butanol to 1-butene (path A) and an ether-mediated conversion of 1-butanol towards 1-butene (path $B+C)[24,33,34]$. To account for the formation of 2-butene isomers the reaction scheme is expanded with double bound isomerization reactions (Paths $F, I$ and $J$ ), direct butanol dehydration towards 2-butenes (path $D$ and $G$ ) and the decomposition of di-n-butylether towards 2butenes (Path $\mathrm{E}$ and $\mathrm{H}$ ), as reported in literature [35]. Double-bond isomerization resulting in isobutene is not depicted as earlier work has shown no iso-butene formation at the low temperatures occurs $[22,36]$. 


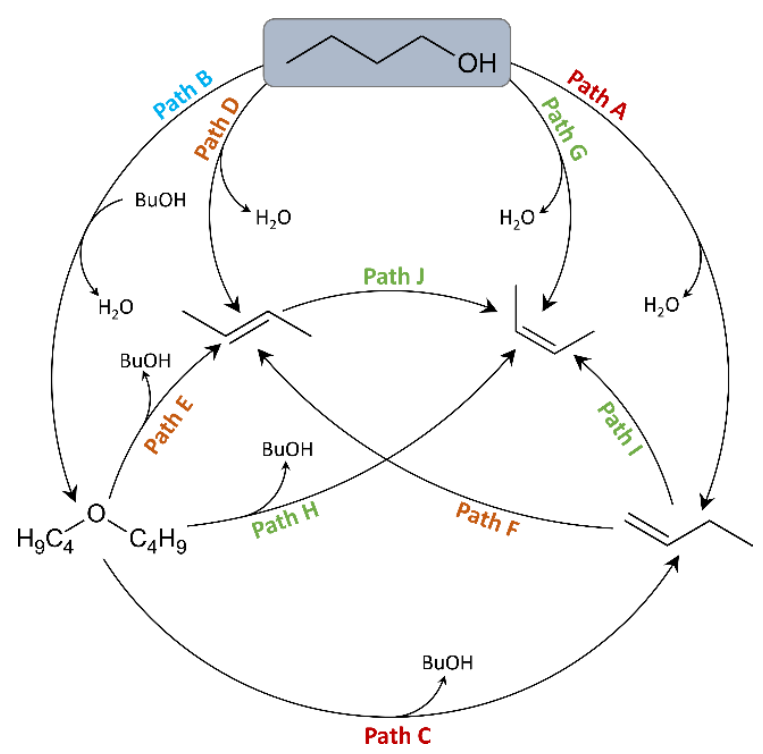

Figure 1: Simplified reaction scheme for 1-butanol dehydration towards butene isomers excluding iso-butene formation. Formation of $n$-butene (red), di-n-butylether (blue), cis-2-butene (green) and trans-2-butene (orange) $[34,35]$

To construct such a 'global' microkinetic model understanding of the most essential zeolite characteristics is necessary, namely its silicon to aluminum ratio $[37,38]$. When decreasing the Si/Al ratio, essentially two characteristics are varied. First the number of acid sites per unit cell is increased as the number of acid sites is related to the aluminum content. But at the same time also the acid strength distribution is affected resulting in a different average acid site strength. It is known that the acid strength of the catalyst can have a big impact on its performance for the dehydration of alcohols to alkenes [39]. It is therefore highly important that these characteristics are compared separately, as both number and strength of acid sites will affect the overall activity of the catalyst, and possibly also the selectivity profiles. Generally, the separation of these characteristics is achieved by comparing results on a site time basis. This parameter is used to account for the number of active sites available in the reactor and is determined as $\left(W \cdot C_{a}\right) / F^{0}$ with $W$ the catalyst mass, $C_{a}$ the number of catalytic sites per gram of catalyst and $F^{0}$ the initial flowrate of the reactant. In this way the effect of the varying number of active sites per gram of catalyst with a change in Si/Al ratio can be excluded by activities at identical site times [32, 34-36].

Research into the effects of the Si/Al ratio on the acid strength indicates that differences are occurring due to the Next Nearest Neighbor (NNN) principle [40], which states that the strength of an acid site is correlated to its neighboring tetrahedral atoms via its atomic bounds. It is generally understood that within the zeolite lattice an increase in the number of Al-atoms on the NNN-locations of the acid sites results in an overall decrease in acid strength [37, 38, 40-43]. Some authors confirm this behavior in alcohol dehydration reactions. Palla et al.[44] briefly investigated the effect of Si/Al ratio on the dehydration of $\mathrm{n}$-butanol towards higher carbons. They tested three different Si/Al ratios for the HZSM5 catalyst at an identical Weight Hourly Space Velocity (WHSV) and noticed a decrease in activity with a decrease in Si/Al ratio. This indicates that even with more acid sites available, due to an increase of aluminum in the lattice and thus the number of acid sites, at the same WHSV, the overall activity of the catalyst is decreased. This decrease in activity enforces the statement that the increase in aluminum content, i.e., a decrease of the Si/Al ratio, results in a weaker average acid site strength. Similar results 
are observed on the dehydration of ethanol to ethylene, which follows the same mechanisms $[13,30$, $31,45]$.

Other authors observe an increase in acid strength for lower Si/Al ratios. Opalka et al. [38] used density functional theory and experimental characterization to investigate this NNN principle. They concluded that an increased aluminum density, corresponding to lower Si/Al ratios, increased the adsorption strength of iso-propyl-amine (and to a lesser extent n-pentane) in HZSM-5 on the acid sites, which is indicative of an increased acid strength. Ferreira et al. [46] used calorimetric methods to determine the heat of adsorption of hexane on HZSM-5 type zeolites and concluded that an increase in aluminum density increased the limiting heat of adsorption of $n$-hexane. Although the dominant interactions for alkanes (physisorption) are different compared to these of alcohols (chemisorption), these experiments support the results found by Opalka et al. Similar findings that contrasts with the common knowledge of the effect of Si/Al on acid strength are also found by work by Wei et al.[47] and AlDughaiter et al.[48]. Both observe an increase in the temperature of the high temperature peak during Temperature Programmed Desorption of $\mathrm{NH}_{3}$ with a decrease of the Si/Al ratio. This increase in temperature indicates an increase in bound strength between $\mathrm{NH}_{3}$ and the acid sites, due to an increased average acid strength.

These contradictions, also recently pointed out by Knott et al. [49], indicate that to get more insight of the effect of the Si/Al ratio on activity and selectivity in alcohol dehydration it is essential to relate the observed effects to individual active sites. Hence, to exclude the effect of the varying number of active sites per gram of catalyst with a change in Si/Al ratio $\left(\mathrm{mol}_{\text {sites }} \mathrm{g}_{\mathrm{cat}}{ }^{-1}\right)$ on the observed activity, the catalytic performance for a series of zeolites is evaluated as function of site time $\left(\mathrm{mol}_{\text {sites }} \mathrm{s} \mathrm{mol}{ }^{-1}\right)$ as opposed to the more frequently used space time $\left(\mathrm{g}_{\mathrm{cat}} \mathrm{s} \mathrm{\textrm {mol } ^ { - 1 } )}\right.$ [43].

In this work we provide a comprehensive study on the effect of the Si/Al ratio of HZSM-5, at four Si/Al ratios of 15, 25, 40 and 140, on the dehydration of 1-butanol at constant partial pressure of butanol of $29 \mathrm{kPa}$ at four temperatures in the range of $503 \mathrm{~K}$ to $533 \mathrm{~K}$. Based on the observed trends and the acid properties of the zeolites determined by $\mathrm{NH}_{3}-\mathrm{TPD}$, we assume that the effect of the $\mathrm{Si} / \mathrm{Al}$ can be related to the variation in average adsorption strength with Si/Al. To validate the assumption of the effect of the $\mathrm{Si} / \mathrm{Al}$ ratio on the butanol dehydration a microkinetic model is utilized.

For the microkinetic model, we started from a 1-butanol dehydration model based on DFT calculations by John et al. [34, 35]. This model was further expanded and modified by fitting key kinetic parameters to the measured data at a $\mathrm{Si} / \mathrm{Al}$ ratio of 25 at four different temperatures, to use as a newly fitted base model to investigate and explain the observed trends with varying Si/Al ratio. Validation of the constructed DFT-based microkinetic model to a robust experimental dataset on the butanol dehydration for a range of $\mathrm{Si} / \mathrm{Al}$ ratios allows to obtain more insight in the effect of process conditions and $\mathrm{Si} / \mathrm{Al}$ ratio on the catalyst performance.

\section{$2 \quad$ Methodology}

\subsection{Catalyst characterization}

Commercial powder zeolites: $\mathrm{NH}_{4}-\mathrm{ZSM}-5$ with a Si/Al ratio of 15 (Zeolyst, CBV 3024E), 25 (Zeolyst, CBV 5524G), 40 (Zeolyst, CBV 8014) and 140 (Zeolyst, CBV 28014) were employed for the catalytic testing. These powders were calcined in air at $823 \mathrm{~K}$ during 8 hours to convert it into its protonated form. The 
calcined sample was subsequently pelletized. After sieving of the pelletized catalysts, the fraction within $75-100 \mu \mathrm{m}$ range were utilized for testing. The Si/Al ratio was verified using ICP-OES. $\mathrm{N}_{2}$ adsorption was performed (Micromeritics Tristar) to determine the surface area and pore volume at $77 \mathrm{~K}$ by means of the BET-method (total surface area $A_{\text {tot }}$ ), the t-plot method (internal surface area: $A_{\text {int }}$ and mesopore volume $V_{\text {macro }}$ ) and the single point adsorption (total pore volume $V_{\text {tot }}$ ). Verification of crystallite sizes below $1 \mu \mathrm{m}$ was performed using SEM. A summary of the catalyst properties is given in Table 1.

Acid sites concentration was determined using $\mathrm{NH}_{3}$-TPD (Micromeritics Autochem). $0.1 \mathrm{~g}$ of dry catalyst was heated to $373 \mathrm{~K}$ during 1 hour under a nitrogen flow. Subsequently the sample was treated with a $4 \mathrm{~mol}_{\%} \mathrm{NH}_{3} / \mathrm{He}$ flow during 1 hour. Afterwards, helium was sent over the sample to remove any excess of $\mathrm{NH}_{3}$ at $373 \mathrm{~K}$. Increasing the temperature to $923 \mathrm{~K}$ at a rate of $10 \mathrm{~K} / \mathrm{min}$ resulted in the desorption of $\mathrm{NH}_{3}$, which was monitored using a thermal conductivity detector (TCD) which was calibrated for $\mathrm{NH}_{3}$ to determine the concentration of acid sites. Deconvolution of the TPD peaks with maxima around 498 $\mathrm{K}$ and $678 \mathrm{~K}$ was performed to respectively determine the amount of weakly and strongly adsorbed ammonia, as illustrated in Figure S1(A) of the Supporting Information. A 1:1 correlation between the amount of strongly adsorbed ammonia and the number of catalytically active acid sites was assumed, which is the total number of active sites $C_{a}$ used to determine site times [30].

Table 1: Catalyst properties: concentration of active sites $\left(C_{a}\right)$, total surface area $\left(A_{\text {tot }}\right)$, external surface area $\left(A_{\text {ext }}\right)$, internal surface area $\left(A_{\text {int }}\right)$, total pore volume $\left(V_{\text {tot }}\right)$, micropore volume $\left(V_{\text {micro }}\right)$ and macropore volume $\left(V_{\text {macro }}\right)$

\begin{tabular}{lccccccc}
\hline Catalyst & ${ }^{1} \mathbf{S i} / \mathrm{Al}$ & $\begin{array}{c}\mathrm{C}_{\mathrm{a}} \\
(\mathbf{m o l} / \mathbf{k g})\end{array}$ & $\begin{array}{c}\mathbf{A}_{\text {ext }} \\
\left(\mathbf{m}^{2} / \mathbf{g}\right)\end{array}$ & $\begin{array}{c}\mathrm{A}_{\text {int }} \\
\left(\mathbf{m}^{2} / \mathbf{g}\right)\end{array}$ & $\begin{array}{c}\mathbf{V}_{\text {tot }} \\
\left(\mathbf{c m}^{3} / \mathbf{g}\right)\end{array}$ & $\begin{array}{c}\mathbf{V}_{\text {micro }} \\
\left(\mathbf{c m}^{3} / \mathbf{g}\right)\end{array}$ & $\begin{array}{c}\mathrm{E}_{\mathrm{d}} \\
(\mathbf{k J} / \mathbf{m o l})\end{array}$ \\
\hline HZSM-5.15 & 14.96 & 0.70 & 123 & 246 & 0.26 & 0.11 & 135.1 \\
HZSM-5.25 & 24.98 & 0.43 & 122 & 242 & 0.26 & 0.11 & 126.3 \\
HZSM-5.40 & 40.01 & 0.27 & 111 & 266 & 0.20 & 0.12 & 110.2 \\
HZSM-5.140 & 140.21 & 0.12 & 140 & 254 & 0.25 & 0.06 & 103.3 \\
\hline
\end{tabular}

The $\mathrm{NH}_{3}$ desorption energy $\left(E_{d}\right)$, can be derived form $\mathrm{NH}_{3}$-TPD profiles with different heating ramps $(\beta)$ and with the maximum desorption temperature $\left(T_{M}\right)$ of the coresponding acid site, located general around $410 \mathrm{~K}$ and desorption surface $\left(A_{d}\right)$ via:

$$
2 \ln T_{M}-\ln \beta=\ln \frac{E_{d}}{R A_{d}}+\frac{E_{d}}{R} \frac{1}{T_{M}}
$$

with $R$ being the universal gas constant. The effect of the different heating rates on the peak location is available in Figure $\mathrm{S} 1(\mathrm{~B})$. In this work, the variation in adsorption strength of ammonia on a series of $\mathrm{H}$-ZSM-5 with varying $\mathrm{Si} / \mathrm{Al}$ as determined by $\mathrm{NH}_{3}$-TPD is taken to mainly reflect changes in average acid strength assuming that solvation effects remain largely the same upon a change in Si/Al.

\subsection{Catalytic testing}

Experimental data acquisition was performed on a high throughput setup consisting of 16 tubular reactors with a length of $0.8 \mathrm{~m}$ and an inner diameter of $0.002 \mathrm{~m}$. The catalyst was loaded in the middle section of the reactors located between inert $\alpha$-alumina, with the catalyst weight ranging from 0.02 to $0.2 \mathrm{~g}$. The catalyst was diluted, before loading, with the same inert material to ensure a uniform temperature profile throughout the catalyst bed. The inert $\alpha$-alumina showed no conversion $(<1 \%)$ in 
the tested temperature range ( $503 \mathrm{~K}-533 \mathrm{~K})$. The temperature range was chosen based on temperature screening performed on H-ZSM-5 with a Si/Al ratio of 25 in previous work, for which sufficient conversion $(0.05-0.95)$ was detected at reasonable site times $(0.1-8.0)$ [36]. The reactors were inserted inside a $\mathrm{SiC}$ heating mantle. A thermocouple inserted into the center of this ceramic heating mantle regulated the temperature of the reaction. A Coriolis flow meter was utilized to regulate the flow rate of 1-butanol (Sigma-Aldrich 99\%+) across a set of 4 tubular reactors. Inert diluent and carrier gas (Helium, Air Liquide, $99 \%+$ ) was fed and regulated by thermal mass flow controllers to achieve an overall reaction pressure of 5 bar within the reactors. Prior to reaction the catalyst bed was heated to reaction temperature and a stabilization period of 1 hour at the set temperature was ensured. To prevent downstream condensation of reaction products all lines were traced and kept at a constant temperature of $413 \mathrm{~K}$. Online GC analysis (equipped with a PONA column) was performed. An internal standard (Methane, Air Liquide, $99 \%+$ ) was added after reaction to check closure of carbon balances within an error of 5\%. A simplified representation of the reactor block consisting out of 4 individual reactors is available in Figure S2 of the supporting information[51]. The closure of the carbon balance ensures the absence of any undetected, additional products such as higher carbons or aromatics and indicates that the removal of butanol can be attributed to the formation of the observed products: din-butylether, 1-butene, trans- and cis-2-butene. To ensure intrinsic kinetics were measured, literature correlations were used [52].

During all experiments, the initial partial pressure of butanol was kept constant at $29 \mathrm{kPa}$. To make a one to one comparison of the catalyst with varying $\mathrm{Si} / \mathrm{Al}$ ratio all comparisons were made based on site time $\left(\left(\mathrm{W} . \mathrm{C}_{\mathrm{a}}\right) / \mathrm{F}_{\mathrm{BuOH}}{ }^{\mathrm{B}}\right)$ to account for the difference in the concentration of active sites. Activity of the catalysts is based on the conversion of butanol $\left(X_{\mathrm{BuOH}}\right)$ and is defined as:

$$
X_{\text {BuOH }}=\frac{F_{B u O H}^{o}-F_{B u O H}}{F_{B u O H}^{o}}
$$

where $F_{\text {BuOH }}^{\circ}\left(\mathrm{mol} \mathrm{s}^{-1}\right)$ is the molar flow rate of butanol at the inlet and $F_{\text {BuOH }}\left(\mathrm{mol} \mathrm{s}^{-1}\right)$ the molar flow rate of butanol at the outlet of the reactor as determined by GC analysis with methane as the internal standard. Carbon selectivity $\left(S_{i}\right)$ towards product is expressed as:

$$
S_{i}=\frac{b_{i} F_{i}}{4\left(F_{B u O H}^{o}-F_{B u O H}\right)}
$$

with $F_{i}$ the outlet flow rate of product $i$ and $b_{i}$ the number of carbon atoms per molecule of product $i$. Also gas phase molar fractions of product $i$ are calculated as:

$$
y_{i}=\frac{F_{i}}{\sum_{i} F_{i}}
$$

Deactivation experiments were conducted as described in previous work [36]. Experimental data were measured at a TOS less than 7 hours where the effects caused by deactivation remain within the limit of the margin of error of $+/-0.05 \mathrm{~mol} / \mathrm{mol}$ conversion. During the deactivation of the catalyst the selectivity of the different products was not affected due to the formation of unidentified species, but solely due to the difference in conversion level. 


\subsection{Microkinetic modeling}

The starting point for the kinetic model in this work is the model reported by John et al. [34], which describes 1-butanol dehydration in HZSM-5 based on Density Functional Theory (DFT) calculations, using the PBE functional [53] with DFT-D2 dispersion corrections [54]. The model of John et al. contains 3 pathways (A, B and C, see Figure 1 ) comprising 23 elementary reaction steps.

This model is further expanded with reaction steps accounting for the formation of 2-butenes taken from another paper by John et al. [35], acquired using the same DFT approach as for the 1-butanol dehydration model. The additional pathways discussed in John et al.[35] are indicated as paths D, E, F, $\mathrm{I}$ and $\mathrm{J}$ in Figure 1 . These reaction paths contain 8 additional elementary steps, resulting in an overall reaction network that comprises 31 reaction steps. Finally two additional paths are introduced, namely paths $\mathrm{G}$ and $\mathrm{H}$, that were mentioned in the work of John et al.[35] but for which no DFT calculations were performed. These paths contribute to the formation of cis-2-butene from $n$-butanol (path $\mathrm{G}$ ) and di-n-butylether (path $\mathrm{H}$ ). These paths are very similar to the mechanisms for the formation of trans-2butene from $n$-butanol (path $\mathrm{D}$ ) and di-n-butylether (path $\mathrm{E}$ ), and therefore the kinetic parameters for the reaction mechanism involving cis-2-butene were copied from the corresponding reaction steps involving trans-2-butene determined by John et al.[35]. For details on the kinetic data the reader is referred to John et al. [34, 35]. Summarized, the starting point for the kinetic modeling was a reaction network consisting of 33 elementary reaction steps which can be interpreted in terms of 10 overall reaction pathways and 18 possible reaction mechanisms (see Supporting Information Table S1 for details).

In a first step, reactor simulations were performed using the kinetic parameters reported by John et al $[34,35]$ and an isothermal plug flow reactor model. The following continuity equations were applied for the gas-phase components $i$ and surface species $k$ along with a site balance:

$$
\begin{gathered}
\frac{d F_{i}}{d W}=R_{i}=C_{a} \sum_{j} v_{j i} T O F_{j} \text { with } F_{i}=F_{i, 0} \text { at } W=0 \\
\frac{d \theta_{k}}{d t}=\sum_{j} v_{j k} T O F_{j}=0 \\
\theta_{*}+\sum_{k} \theta_{k}=1
\end{gathered}
$$

where $T O F_{j}$ is the turnover frequency of elementary step $j\left(\mathrm{~mol} \mathrm{~mol}_{\mathrm{H}^{-}}{ }^{-1} \mathrm{~s}^{-1}\right), v_{j i}$ the stoichiometric coefficient of component $i$ in the elementary step $j, \theta_{k}$ the fractional coverage of surface species $k$ (mol $\left.\mathrm{mol}_{\mathrm{H}+}^{-1}\right), \theta *$ the fractional coverage of free active sites $\left(\mathrm{mol} \mathrm{mol}_{\mathrm{H}^{-}}{ }^{-1}\right), \mathrm{C}_{a}$ the concentration of active sites $\left(\mathrm{mol}_{\mathrm{H}+} \mathrm{kg}^{-1}\right), F_{i}$ the molar flow rate of gas-phase component $i\left(\mathrm{~mol} \mathrm{~s}^{-1}\right), W$ the mass of the catalyst $(\mathrm{kg})$ and $R_{i}$ the net production rate of gas-phase species $i\left(\mathrm{~mol} \mathrm{~kg}^{-1} \mathrm{~s}^{-1}\right)$. This set of equations was solved numerically using the LSODA module of ODEPACK.

Next, to investigate which key parameters control the model output, a degree of rate control was performed as described by Stegelmann et al. [55]. Transition state energies were increased by 0.1 $\mathrm{kJ} / \mathrm{mol}$ resulting in a decrease of both the forward and the reverse rate coefficient for an elementary step. The degree of rate control of this step on the activity and selectivity was obtained as: 


$$
X_{T R C, n}=\frac{\partial \ln r_{i}}{\partial\left(\frac{-G_{n}^{0}}{R T}\right)}
$$

With $r_{i}$ being the net rate of formation of component $i, G_{n}^{0}$ the standard-state molar free energy for transition state $n, R$ the universal gas constant and $T$ the temperature. Analysis was performed at a temperature of $513 \mathrm{~K}$ as the bulk of experimental data is acquired at this temperature.

Then, the key microkinetic model parameters were updated by fitting to the experimental data using the Least Squares approach. Residuals were determined by the relative error of the calculated to the experimental flow rates. These residuals were then used to determine the Residual Sum of Squares (RSSQ) across all components and all experimental results:

$$
R S S Q=\sum_{l} \sum_{i}\left(\frac{F_{i l}^{m}-F_{i l}}{F_{i l}^{m}}\right)^{2}
$$

With $F_{i l}^{m}$ the model-predicted outlet flow of component $i$ in experiment number $I, F_{i l}$ the experimental outlet flow of component $i$ in experiment number $I$.

The fitting process was performed at the four temperatures to acquire the Gibbs energy of activation $\left(\Delta G^{\ddagger}\right)$ for each key transition state at each temperature. These acquired Gibbs energies where plotted against the temperature at which they were obtained to separate the contribution of enthalpy $\left(\Delta \mathrm{H}^{\ddagger}\right)$ and entropy $\left(\Delta S^{\ddagger}\right)$. The activation energy $\left(E_{a(f)}\right)$ and pre-exponential factor $\left(A_{f}\right)$ for the forward reaction step are derived from the activation enthalpy and entropy as follows:

$$
\begin{gathered}
E_{a(f)}=\Delta H^{\ddagger}+R \cdot T_{a v} \\
A_{f}=\frac{k_{b} \cdot T_{a v}}{h} \cdot e^{1+\frac{\Delta S^{\ddagger}}{R}}
\end{gathered}
$$

With $T_{a v}$ the average temperature across the tested temperature range, i.e., $518 \mathrm{~K}$, $\mathrm{k}_{\mathrm{b}}$ the Boltzman constant and $\mathrm{h}$ Planck's constant. Reverse activation energies and pre-exponential factors are modified accordingly to ensure equilibrium values are not affected. By separation of these two contributions the acquired model can predict temperature effects at other temperatures.

\section{$3 \quad$ Results and discussion}

\subsection{Experimental effect of Si/Al ratio}

To investigate the effect of the Si/Al ratio within a specific zeolite lattice, in this case HZSM-5, a full conversion and selectivity analysis was performed under dehydration conditions. The activity is expressed per site time, which accounts for the different number of acid sites per catalyst mass and therefore ensures to exclude effects caused by the difference in acid site density on the activity. The obtained conversion versus site time plot is shown in Figure 2. 


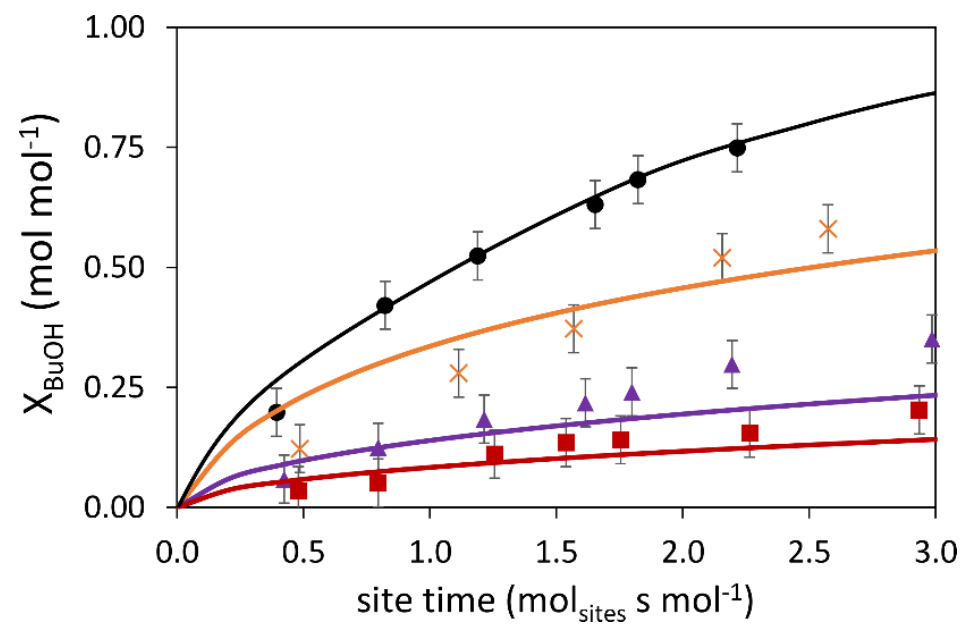

Figure 2: Conversion (Хвион) as function of site time for HZSM-5 at four different Si/Al ratios: 15 ( $\square$, red), 25( $\triangle$, blue), $40\left(\times\right.$, orange) and $140\left(\bullet\right.$, black) at $513 \mathrm{~K}$ and $\mathrm{P}^{0}{ }_{\mathrm{BuOH}}=29 \mathrm{kPa}$. Lines are added to guide the eye. Error bars represent the $95 \%$ confidence interval determined by repetition experiments.

As can be observed in Figure 2, a decrease in $\mathrm{Si} / \mathrm{Al}$ ratio leads to an increase in activity. This indicates a significant effect of the $\mathrm{Si} / \mathrm{Al}$ ratio on the catalyst activity. These trends contradict the general understanding of the NNN principle [40], which states that an increase in Al-atoms in the vicinity of other $\mathrm{Al}$ atoms (i.e., a decrease in $\mathrm{Si} / \mathrm{Al}$ ratio) decreases the overall acid strength of acid sites, resulting in a decrease in activity. In agreement with the observed experimental results in this work, Semelsberger et al. [56] observed a strong decrease in activity for the hydrolysis of dimethylether on HZSM-5 when increasing the Si/Al ratio from 40 to 140 .

Regarding selectivity no significant differences with varying Si/Al ratio are observed over the full conversion range, as illustrated in Figure 3. Clearly, double bound isomerisation increases with an increase in conversion. As 1-butene selectivity remains roughly constant around $0.2 \mathrm{~mol} / \mathrm{mol}$, the cisand trans-isomers selectivity steadily increases from 0.05 to 0.32 for cis-butene and from 0.1 to 0.52 for trans-butene. No iso-butene is detected under these conditions, which is in agreement with the general assumption that higher temperatures are requierd for skeletal isomerization to occur [22, 36]. However, these trends are in contrast to Palla et al. [44] who observed a change in selectivities with changing the Si/Al ratio within HZSM-5 at identical WHSV of $2.99 \mathrm{~h}^{-1}$ : for a decrease in Si/Al ratio the intermediary ether is decomposed at higher conversion, whilst the butene isomer formation is increased. But it has to be noted that these claims were made at different conversion level $(84 \%, 96 \%$ and $97 \%$ ), rather than at the same site time, which most likely would have resulted in the same conversions and selectivities. In this work, selectivities are compared at identical conversion of butanol.

Similar results to the work of Palla et al. [44] on butanol dehydration, were observed by Talukdar et al. [45] for the dehydration of ethanol. They noticed that selectivity towards oligomerization and cracking products increased with a lower Si/Al ratio. Their work compared selectivities at identical WHSV, which again neglects the varying number of active sites. Van der Borght et al. [30] investigated the effect of site time, which includes the change in the number of active sites, on the dehydration of ethanol on H-ZSM-5 to higher carbons and concluded that the site time has significant effects on the selectivity, even when full conversion of ethanol is reached. It is thus impossible to correlate the effect of Si/Al ratio with experiments which do not account for the number of active sites of each catalyst. 


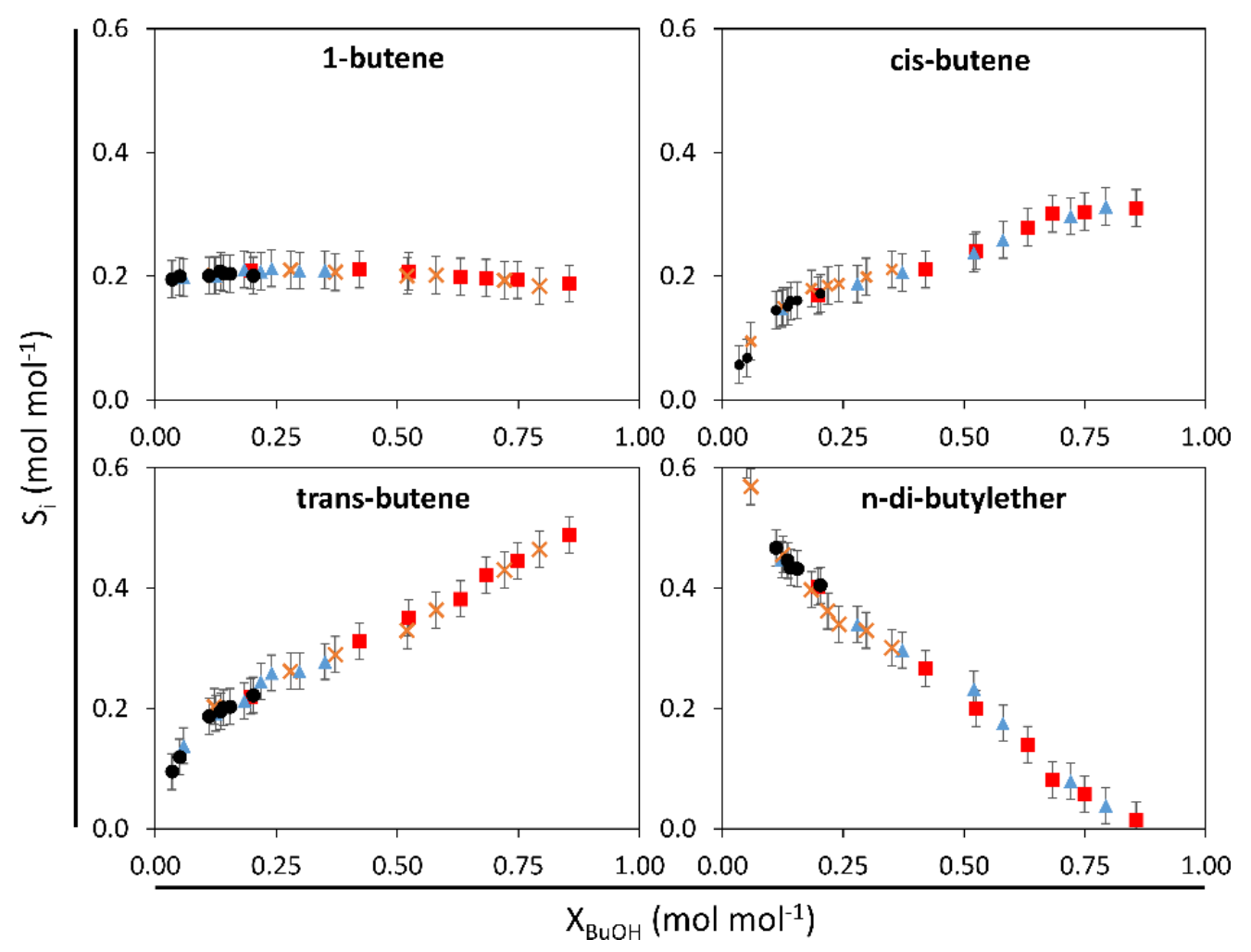

Figure 3: Selectivity $\left(S_{i}\right)$ of the different reaction products (1-butene, cis-butene, trans-butene and di-nbutylether) as function of conversion $\left(X_{B u O H}\right)$ for four different Si/Al ratios of HZSM-5 (15 ( $\mathbf{\square}$, red), 25( $\mathbf{\Lambda}$, blue), $40(\times$, orange $)$ and $140(\bullet$, black $)) .\left(P_{\mathrm{BuOH}}^{\mathrm{O}}=29 \mathrm{kPa}, T=513 \mathrm{~K}\right)$. Error bars represent the $95 \%$ confidence interval.

The shift in activity without affecting the selectivity-conversion relation is a concept that has been extensively found for the catalytic cracking of alkenes over different zeolites with different acid strength distributions [57,58]. Dumesic et al. [59] related these trends to the average acid strength of the catalyst. With the aid of microkinetic modeling a catalyst descriptor $\Delta \mathrm{H}^{+}$was introduced, which represented the stabilization enthalpy of the alkylcarbenium ion by the zeolite, relative to the stabilization enthalpy of a proton by the zeolite. This catalyst descriptor equally affects all the carbenium-like species (intermediates and transition states), resulting in the typicall shift of activity without affecting the selectivities. This descriptor has a clear relation to the acid strength distribution of the zeolite as the stabilization of these carbenium species occurs at the acid sites within the zeolite [60]. This approach has been widely utillized to explain the effects of acid strength distribution within one specific type of zeolite for cracking reactions [61-64] and to model the effect of different Si/Al ratios within a single zeolite [65-67], as the Si/Al ratio can be related to a change in average acid strength.

This approach could possibly be employed to explain our observed experimental results in the dehydration of butanol, as similar trends in activity and selectivity as function of the Si/Al ratio can be observed for the dehydration of $n$-butanol and cracking reactions on HZSM-5. As shown in Table 1 , the desorption energy of $\mathrm{NH}_{3}$ drops from $135 \mathrm{~kJ} \mathrm{~mol}^{-1}$ for a Si/Al of 15 towards $103.3 \mathrm{~kJ} \mathrm{~mol}^{-1}$ for the Si/Al value of 140 indicating a rather large effect of the Si/Al ratio on the adsorption capability of HZMS-5. This relation is in accordance with work by Ferreira et al. [46] and Opalka et al. [38] who studied the adsorption of different molecules, hexane and iso-propylamine respectivly, in HZSM-5 and report an increase (more negative) in adsorption enthalpy with decreasing Si/Al relation. 


\subsection{Microkinetic modeling for Si/Al ratio $=25$}

To understand and validate the effect of $\mathrm{Si} / \mathrm{Al}$ ratio on the dehydration reaction a microkinetic model is constructed based on a model reported by John et al [34,35] for H-ZSM-5 with a Si/Al ratio of 95 . This base model is further modified as described in section 0 . All elementary steps can be consulted in Table S1 with their kinetic parameters in table S2 in the supporting information. Visualization of the chemical structure of each surface species is also available in Figure S3. As described in section 0, the key transition states were identified for activity and selectivity towards all formed products based on a degree of rate control analysis. Results of this analysis can be found in Table 2.

Table 2: Degree of rate control analysis $\left(X_{T R C, n}\right)$ results for all transition states in the used microkinetic model based on literature by John et al. [34,35] at $513 \mathrm{~K}$ at a site time of $1.05 \mathrm{~mol} \mathrm{~s} \mathrm{~mol}^{-1}$. Analysis was used to investigate the effect of the conversion, represented as Activity, and the Selectivity of the four formed components 1-butene, di-n-butylether (DBE), cis-2-butene and trans-2-butene. Bold reactions indicate identified key elementary reaction steps. Elementary steps not shown in this table are equilibrated.

\begin{tabular}{|c|c|c|c|c|c|c|}
\hline \multirow[b]{2}{*}{${ }^{\circ}$ Elementary steps } & \multirow{2}{*}{$\begin{array}{c}\text { Transition } \\
\text { states }\end{array}$} & \multirow[b]{2}{*}{ Activity } & \multicolumn{4}{|c|}{ Selectivity } \\
\hline & & & 1-butene & DBE & $\begin{array}{l}\text { cis-2- } \\
\text { butene }\end{array}$ & $\begin{array}{l}\text { trans-2- } \\
\text { butene }\end{array}$ \\
\hline${ }^{1} \mathrm{M} 1 \leftrightarrow \mathrm{W}+1$-butene $(\mathrm{g})$ & TS1 & 0.00 & 0.00 & 0.00 & 0.00 & 0.00 \\
\hline${ }^{3} \mathrm{M} 1 \leftrightarrow \mathrm{C} 1$ & TS2 & 0.00 & 0.01 & -0.01 & 0.00 & 0.00 \\
\hline${ }^{6} \mathrm{M} 2 \leftrightarrow$ 1-butene* $+\mathrm{H}_{2} \mathrm{O}_{(\mathrm{g})}$ & TS3 & 0.01 & 0.35 & -0.51 & -0.05 & -0.05 \\
\hline${ }^{8} \mathrm{M} 2 \leftrightarrow$ butoxy $+\mathrm{H}_{2} \mathrm{O}$ & TS4 & 0.00 & 0.00 & 0.02 & 0.00 & 0.00 \\
\hline${ }^{9}$ butoxy $\leftrightarrow 1$-butene* & TS5 & 0.00 & 0.03 & -0.06 & 0.00 & 0.00 \\
\hline${ }^{12} \mathrm{D} 2 \leftrightarrow \mathrm{C} 2+1$-butene $(\mathrm{g})$ & TS6 & 0.00 & 0.01 & -0.01 & 0.00 & 0.00 \\
\hline${ }^{14} \mathrm{D} 2 \leftrightarrow \mathrm{DBE}^{*}+\mathrm{H}_{2} \mathrm{O}_{(\mathrm{g})}$ & TS7 & 0.17 & 0.02 & 0.57 & 0.05 & 0.05 \\
\hline${ }^{17} \mathrm{C} 3 \leftrightarrow \mathrm{DBE}^{*}(\mathrm{Sn} 2)$ & TS8 & 0.00 & 0.00 & 0.00 & 0.00 & 0.00 \\
\hline${ }^{18} \mathrm{C} 3 \leftrightarrow \mathrm{DBE} *(\mathrm{Sn} 1)$ & TS9 & 0.00 & 0.00 & 0.00 & 0.00 & 0.00 \\
\hline${ }^{19} \mathrm{DBE}^{*} \leftrightarrow \mathrm{C} 4$ & TS10 & 0.00 & 0.86 & -1.57 & -0.01 & -0.01 \\
\hline${ }^{22} \mathrm{DBE} 2 \leftrightarrow$ 1-butene* $+\mathrm{BuOH}_{(\mathrm{g})}$ & TS11 & 0.00 & 0.00 & 0.00 & 0.00 & 0.00 \\
\hline${ }^{23} \mathrm{D} 1 \leftrightarrow \mathrm{C} 2+$ trans-2-butene $(\mathrm{g})$ & TS12 & 0.00 & 0.00 & 0.00 & 0.00 & 0.00 \\
\hline${ }^{24}$ DBE* $\leftrightarrow$ M1 + trans-2-butene $(\mathrm{g})$ & TS13 & 0.00 & 0.00 & -0.46 & 0.00 & 1.00 \\
\hline${ }^{25}$ 1-butene* $\leftrightarrow$ trans-2-butene* & TS14 & 0.00 & 0.00 & 0.00 & 0.00 & 0.00 \\
\hline${ }^{27} 1$-butene* $\leftrightarrow 2$-butoxy & TS15 & 0.00 & 0.00 & 0.00 & 0.00 & 0.00 \\
\hline${ }^{28} 2$-butoxy $\leftrightarrow$ trans-2-butene* & TS16 & 0.00 & 0.00 & 0.00 & 0.00 & 0.00 \\
\hline${ }^{29} \mathrm{D} 1 \leftrightarrow \mathrm{C} 2+$ cis-2-butene $(\mathrm{g})$ & TS18 & 0.00 & 0.00 & 0.00 & 0.00 & 0.00 \\
\hline${ }^{30} \mathrm{DBE}^{*} \leftrightarrow \mathrm{M} 1+$ cis-2-butene $(\mathrm{g})$ & TS19 & 0.00 & 0.00 & -0.46 & 1.00 & 0.00 \\
\hline${ }^{31}$ 2-butoxy $\leftrightarrow$ cis-2-butene* & TS17 & 0.00 & 0.00 & 0.00 & 0.00 & 0.00 \\
\hline
\end{tabular}

Five key reaction steps where determined: (i) reaction 6 , the formation of adsorbed 1-butene (butene*) and gaseous water from absorbed butanol species (M2); (ii) reaction 14, the formation of adsorbed din-butylether (DBE*) from adsorbed butanol dimer surface species (D2); (iii) reaction 19, the decomposition of adsorbed di-n-butylether (DBE*) towards co-adsorbed 1-butene and n-butanol (C4) (iv) reaction 24, the direct decomposition of $\mathrm{DBE}^{*}$ towards gaseous trans-2-butene and adsorbed butanol (M1) and (v) reaction 30, direct decomposition of DBE* towards gaseous cis-2-butene and adsorbed butanol (M1). Visualization of all surface species is available in Figure S3 of the supporting information. For these reactions linear regression of the Gibbs energies of activation $\left(\Delta G^{\ddagger}\right)$ was 
performed as stated in section 0 on a data set acquired on a HZSM- 5 catalyst with a Si/Al ratio of 25 over a site time range of $0-10 \mathrm{~mol} \mathrm{~s} \mathrm{~mol}^{-1}$ at 4 different temperatures $(503 \mathrm{~K}, 513 \mathrm{~K}, 523 \mathrm{~K}$ and $533 \mathrm{~K}$ ). From $\Delta \mathrm{G}^{\ddagger}$ as a function of temperature, the activation energies and pre-exponential factors for the key reactions are obtained.

Initial linear regression with these 5 parameters gave an inadequate fit and could not predict the formation of 2-butene isomers at very low conversion. To account for these effects two reaction steps were included in the regression: reaction 23 and 29, i.e., the formation of gaseous trans-2-butene and cis-2-butene from adsorbed butanol dimer surface species D1. These steps were chosen as these are the only elementary steps that result in the direct formation of cis- and trans-2-butenes from butanol. These reaction steps initially had high energy barriers, resulting in low contributions of these paths to gaseous species. This possibly explains the lack of sensitivity found in the degree of rate control, as a small change in the Gibbs energy will not result in sufficient changes to the overall selectivity and/or activity. The Gibbs energies of activation of these in total 7 key reactions were used as variables for the fitting process with the experimental results, for a silica to alumina ratio of 25 , as described in section 0 . The results of this process are shown in Table 3.

Table 3: Forward activation energy with $95 \%$ confidence intervals $\left(E_{a(f)}\right)$, pre-exponential factors $\left(A_{f}\right)$ and rate coefficients at $513 \mathrm{~K}$ obtained from parameters estimation vs. the original DFT-calculated values from John et al. $[34,35]$.

\begin{tabular}{|c|c|c|c|c|c|c|}
\hline \multirow[b]{2}{*}{${ }^{n^{\circ}}$ Reactions } & \multicolumn{2}{|c|}{$\mathbf{E}_{\mathrm{a}(\mathrm{f})}\left(\mathrm{kJ} \mathrm{mol}^{-1}\right)$} & \multicolumn{2}{|c|}{$\mathbf{A}_{f}\left(s^{-1}\right)$} & \multicolumn{2}{|c|}{$\mathbf{k}_{\mathrm{f}(513 K)}\left(s^{-1}\right)$} \\
\hline & $\begin{array}{l}\text { John } \\
\text { et al. }\end{array}$ & $\begin{array}{l}\text { This } \\
\text { work }\end{array}$ & John et al. & $\begin{array}{l}\text { This } \\
\text { work }\end{array}$ & $\begin{array}{c}\text { John et } \\
\text { al. }\end{array}$ & $\begin{array}{l}\text { This } \\
\text { work }\end{array}$ \\
\hline${ }^{6} \mathrm{M} 2 \leftrightarrow 1$-butene* $+\mathrm{H}_{2} \mathrm{O}_{(\mathrm{g})}$ & 53 & $45 \pm 3$ & $9,0 \times 10^{14}$ & $8,9 \times 10^{14}$ & $3,61 \times 10^{9}$ & $2,21 \times 10^{10}$ \\
\hline${ }^{14} \mathrm{D} 2 \leftrightarrow \mathrm{DBE}^{*}+\mathrm{H}_{2} \mathrm{O}_{(\mathrm{g})}$ & 93 & $102 \pm 3$ & $1,4 \times 10^{14}$ & $1,4 \times 10^{14}$ & $4,75 \times 10^{4}$ & $5,35 \times 10^{3}$ \\
\hline${ }^{19} \mathrm{DBE}^{*} \leftrightarrow \mathrm{C} 4$ & 140 & $163 \pm 4$ & $2,5 \times 10^{14}$ & $2,5 \times 10^{14}$ & $1,39 \times 10^{0}$ & $5,65 \times 10^{3}$ \\
\hline${ }^{23} \mathrm{D} 1 \leftrightarrow \mathrm{C} 2+$ trans-2-butene $(\mathrm{g})$ & 201 & $165 \pm 4$ & $4,9 \times 10^{15}$ & $4,9 \times 10^{15}$ & $1,67 \times 10^{-5}$ & $7,34 \times 10^{2}$ \\
\hline${ }^{24} \mathrm{DBE}^{*} \leftrightarrow \mathrm{M} 1+$ trans-2-butene $(\mathrm{g})$ & 171 & $174 \pm 4$ & $3,8 \times 10^{15}$ & $3,8 \times 10^{15}$ & $1,47 \times 10^{-2}$ & $6,96 \times 10^{3}$ \\
\hline${ }^{29} \mathrm{D} 1 \leftrightarrow \mathrm{C} 2+$ cis-2-butene $(\mathrm{g})$ & $201^{a}$ & $169 \pm 4$ & $4,9 \times 10^{15 a}$ & $4,9 \times 10^{15}$ & $1,67 \times 10^{-5}$ & $3,33 \times 10^{2}$ \\
\hline${ }^{30} \mathrm{DBE}^{*} \leftrightarrow \mathrm{M} 1+$ cis-2-butene $(\mathrm{g})$ & $171^{\mathrm{a}}$ & $173 \pm 4$ & $3,8 \times 10^{15} \mathrm{a}$ & $3,8 \times 10^{15}$ & $1,47 \times 10^{-2}$ & $1,01 \times 10^{2}$ \\
\hline
\end{tabular}

To achieve a good agreement between the experimental result and the results of the micro kinetic model, shown in Figure 4 and Figure 5, the generally minor adjustments shown in Table 3 were necessary. Overall the re-estimation of the activation energy of the identified key reaction steps were essential to achieve an appropriate fit of the model with the experimental results, whilst preexponential factors remained unaltered. The activation energy of the parameters that were selected based on the degree of rate control remain, also after the parameter regression procedure, very close to the original ab initio values of John et al. (changes of the order of several $\mathrm{kJ} / \mathrm{mol}$ with an outlier to $23 \mathrm{~kJ} / \mathrm{mol}$ ). This illustrates that the actual chemistry very likely follows the DFT-predicted reaction pathways. Nonetheless, these small changes are essential to achieve an adequate agreement of the model predictions with the experimental results. The activation energies of the parameters which enable the formation of 2-butene isomers at very low conversion (reaction 23 and 29) were modified by larger amounts, -40 and $-37 \mathrm{~kJ} / \mathrm{mol}$ for reaction steps 23 and 29 respectively. Probably this reaction, the formation of 2-butenes of the D1 intermediate, follows a different (lower activated) mechanism than assumed in the DFT modeling. 


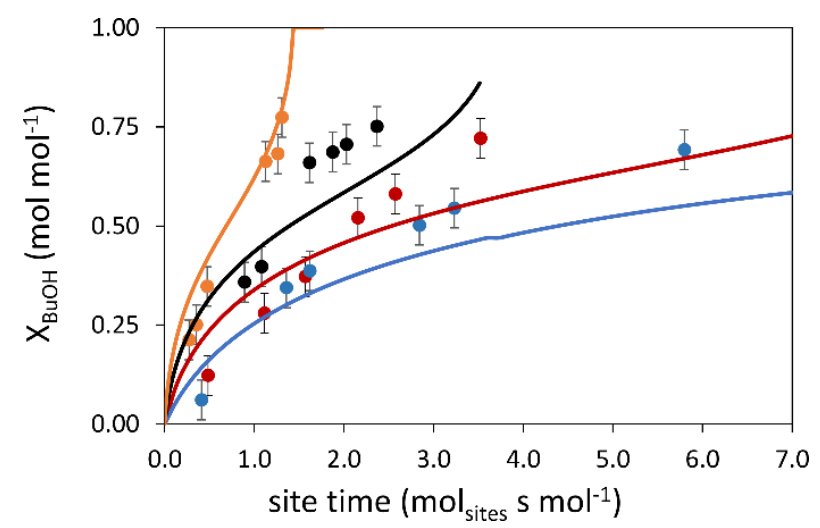

Figure 4: $\mathrm{X}_{\mathrm{BuOH}}$ as function of site time for HZSM-5 at four different temperatures: $503 \mathrm{~K}$ (blue), $513 \mathrm{~K}$ (red), 523K (black) and $533 \mathrm{~K}$ (orange) at $\mathrm{p}^{0}{ }_{\mathrm{BuOH}}=29 \mathrm{kPa}$ and a Si/Al ratio of 25 . Lines represent model simulated results with re-estimated transition states. Error bars represent the $95 \%$ confidence interval.

With these estimated parameters, an adequate fit is achieved with the experimental results as shown in Figure 4 and Figure 5. Fitting of the model parameters thus results in an overall increase of the activity as compared to the original DFT model, which is also reflected in a decrease of $8 \mathrm{~kJ} / \mathrm{mol}$ in the apparent activation energy and in the energetic span[68], visualized in Figure S4 of the Supporting Information and is related to a decrease in the activation energy of reaction 6 . Simulated conversion as a function of site time shows the best agreement to experimental results at the highest temperature (see Figure 4). As temperature is decreased, a less adequate fit is found with the experimental data. It does however indicate a trend of decreased activity with lower temperatures. As for selectivities, an excellent agreement with the experimental data across the four different temperatures is achieved (see Figure 5).

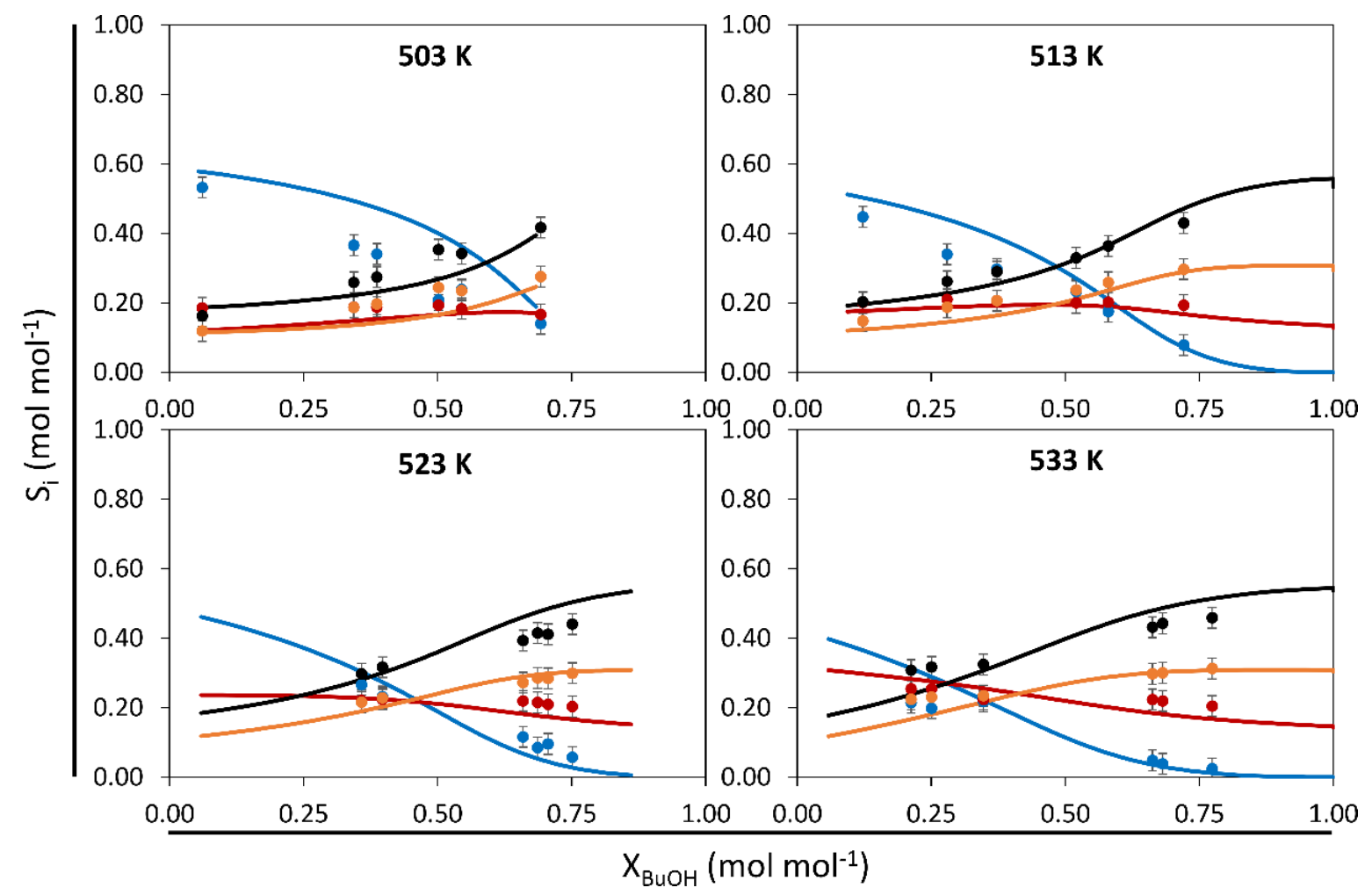

Figure 5: Selectivity $\left(\mathrm{S}_{\mathrm{i}}\right)$ as a function of conversion $\left(\mathrm{X}_{\text {вион }}\right)$ at four different temperatures: $503 \mathrm{~K}, 513 \mathrm{~K}, 523 \mathrm{~K}$ and 533 of the different reaction products (1-butene (red), cis-2-butene (orange), trans-2-butene (black) and di-nbutylether (blue)). Lines represent model simulated results with re-estimated parameters (see Table 3). $\left(\mathrm{p}^{0}{ }_{\text {BuOH }}=29 \mathrm{kPa}, \mathrm{Si} / \mathrm{Al}=25\right)$. Error bars represent the $95 \%$ confidence interval. 
A peculiar experimental trend, for the three highest temperatures, is also predicted by the model where the conversion of butanol, which typically slows down with increasing site time, increases rapidly after a certain point of conversion. Across the three highest temperatures, the point of change is around $0.65 \mathrm{~mol} / \mathrm{mol}$ conversion as seen in Figure 4 . It is also clearly visible that the selectivity at low conversion is highly affected by the increase in temperature. The biggest changes are related to the selectivity towards 1-butene and di-n-butylether: with increasing temperature the formation of 1butene is increased at the cost of the formation of the ether. Generally, the di-n-butylether formation is suppressed whilst the formation of all butenes is increased with increasing temperature.

Investigation of the reaction rates of the different significant paths depicted in Figure 1 show that some paths are more effected by the increase of temperature, see Figure 6 (details for all paths for the formation of each gaseous species can be found in Figure $\mathrm{S} 5$ in the supporting information). Paths absent in Figure 6 are paths $\mathrm{C}, \mathrm{E}$ and $\mathrm{H}$ which are all related to decomposition of di-n-butylether towards 1-butene, trans-2-butene and cis-2-butene respectively. This indicates that the decomposition of di-n-butylether in general is not the dominant mechanism for the formation of butenes, occurring at the tested temperature ranges. The dominant mechanism for the formation of butenes is generally occurring via the direct pathways being Path $A, D$ and $G$ for 1-butene, trans-2-butene and cis-2-butene respectively. Also, path $\mathrm{J}$, the cis-trans isomerization of 2-butene, is not shown since this reaction pathway is not occurring in the tested ranges. All formation of cis-2-butene is occurring via isomerization of 1-butene (path I).

The top panels of Figure 6 show a strong increase of the net reaction rate of path A (light green) with increasing temperature compared to others, especially compared to the rate of path $B$ (blue). This explains the shift of the increased selectivity towards 1-butene, whilst decreasing the formation of di$n$-butylether as path $A$ is the direct formation of 1-butene and path $B$ the formation of di-n-butylether. Also a large shift in overall dominant pathway is occurring at each temperature, namely from path $B$ to path $A$. This shift is occurring at a lower conversion with an increase in temperature, which also explains the difference in selectivity across the full conversion range, towards di-n-butylether observed in Figure 5 with an increase in temperature. Also, for the formation of 2-butenes a shift in dominant path is also occurring. At low conversion the formation of trans- and cis-2-butene is dominated by direct formation from the adsorbed dimer $\mathrm{D} 1$ (paths $\mathrm{D}$ (black) and $\mathrm{G}$ (yellow) respectively), whilst at higher conversion the dominant path is shifted to the isomerization paths starting from 1-butene* over 2-butoxy (paths F(orange) and I(grey) respectively). 

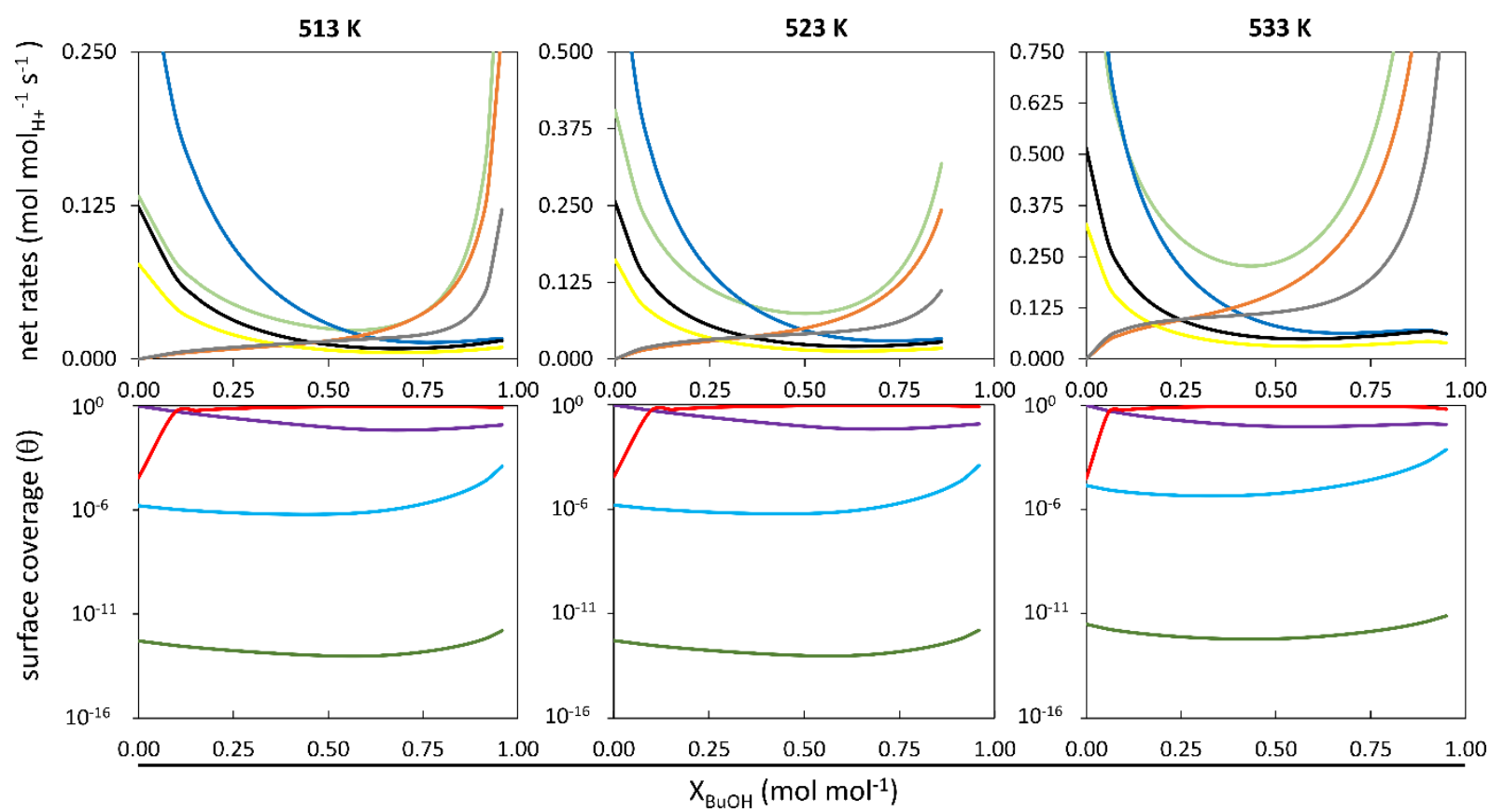

Figure 6: Model simulated net rates (top half) for the different paths (Path A: light green; Path B: blue; Path D: black; Path F: orange; Path G: yellow; path I: grey) which account for the largest contribution for the formation of gaseous species and model simulated surface coverages (bottom half) of interesting species (DBE*: red; free sites: Light blue; D1: purple; M2: green) as function of conversion ( $\left.\mathrm{В}_{\mathrm{BuOH}}\right)$ at 3 different temperatures which show an Slike conversion profile $(513 \mathrm{~K}, 523 \mathrm{~K}$ and $533 \mathrm{~K})$ at $\mathrm{p}^{0}{ }_{\mathrm{BuOH}}=29 \mathrm{kPa}$ and a Si/Al of 25.

As for surface coverage it is clearly visible that the surface is dominated by adsorbed di-n-butylether (DBE*, red) and adsorbed butanol dimer D1 (purple). The high coverage of these species is strongly related to the low Gibbs energies of these intermediates, which are the most negative of all surface species. A representation of the standard Gibbs energies, at 513K, of all surface species is available in Figure $\mathrm{S} 6$ of the Supporting information. The coverage of DBE* reaches a maximum for a conversion of 0.45 to 0.7 , which is clearer with the non-logarithmic scale in Figure 7.

These maxima in DBE* coverage (in Figure 7) across the three temperatures can be linked to the 'Slike' conversion profile of Figure 4: a shift of these maxima to lower conversion occurs at an increased temperature, but also a decrease in maximum surface coverage. Comparing the location of these maxima of the DBE* coverage it is indicated that the inflection point on the conversion S-curve is occurring at exactly the point of maximal DBE* coverage. This indicates an inhibition effect caused by the adsorbed di-n-butylether. As the surface is 'poisoned' by the strongly adsorbed ether all rates decrease (as is indicated in Figure 6), decreasing the overall activity and thus conversion of $n$-butanol. After reaching the adsorbed maximum, the inhibition effect decreases and the overall activity of the catalyst will increase. This explains the peculiar experimental trend for the conversion of $n$-butanol, which is particularly strong at the highest temperature of 533K. 


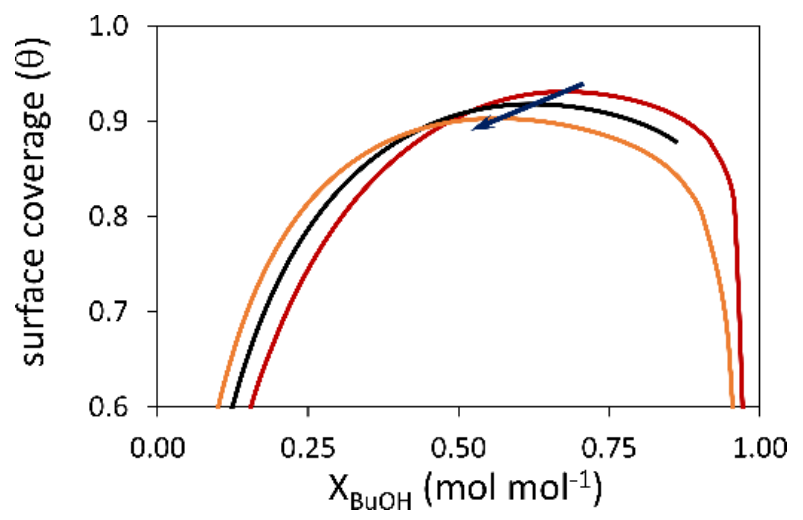

Figure 7: Model simulated surface coverage of adsorbed di-n-butylether $(\theta)$ as function of conversion $\left(\mathrm{X}_{\mathrm{BuOH}}\right)$ at $513 \mathrm{~K}$ (red), 523K (black) and 533K (orange), $\mathrm{p}^{0}{ }_{\mathrm{BuOH}}=29 \mathrm{kPa}$ and $\mathrm{Si} / \mathrm{Al}=25$.

It is also worthwhile to have a closer look on the fraction of free sites in Figure 6, as these will have a large effect on the overall activity of the catalyst, the fraction $M 2$, which is the key intermediate for the reaction path $A$ involving the direct formation of 1-butene and D1, the second most abundant surface species. All these coverages show a minimum as function of the conversion and a shift with increasing temperature towards lower conversion is also clearly visible. These 'key points' always occur in a fixed sequence and eventually contribute in the maximum of DBE* coverage, see Figure 8. With increasing conversion, first the number of free sites reaches a minimum, followed by a minimum in coverage of the path A intermediate $M 2$, with lastly the maximum DBE* coverage closely followed by a minimum in D1. Due to this sequence the maximal coverage of di-n-butylether is reached: as more active sites become available, the key intermediate for the competitive path $A(M 2)$ increases, leading towards a proportional lower formation of di-n-butylether resulting in the maximum of ether coverage. A visualization of this sequence of events, and other interesting events, is visualized in Figure 8. This figure also clarifies the similar site times for the inflection point and the maximum coverage of DBE*. Another interesting aspect is the shift in dominant pathway, which is highly affected by the temperature, as the tipping point is located at a site time of $0.05,0.64$ and 3.23 for $533 \mathrm{~K}, 523 \mathrm{~K}$ and $513 \mathrm{~K}$ respectively.

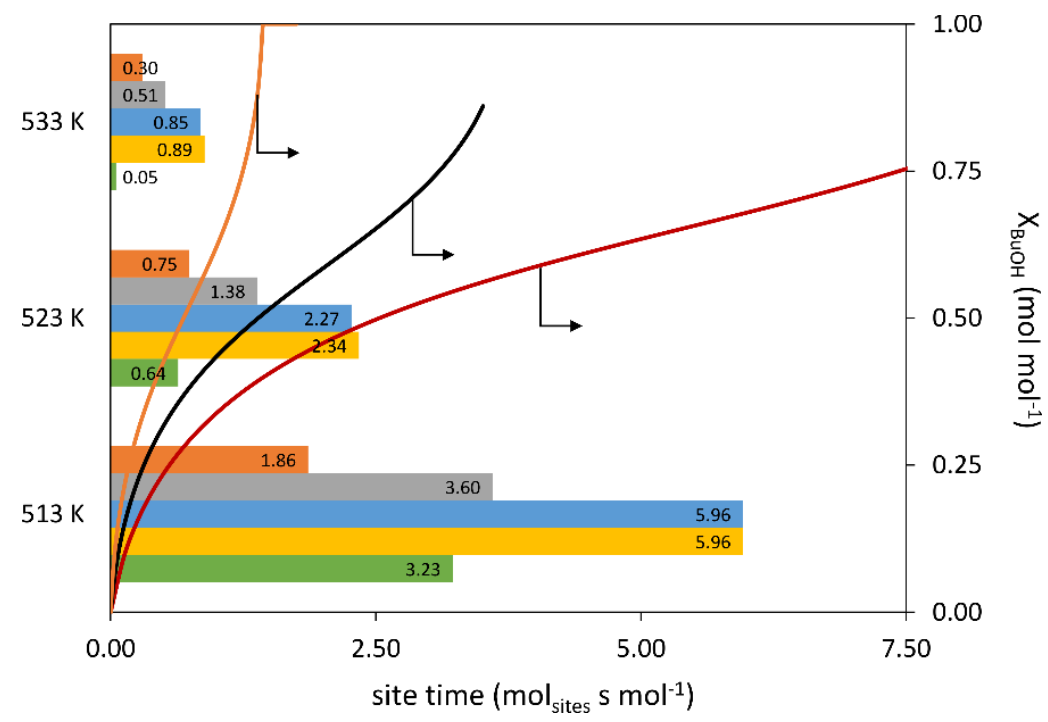

Figure 8: Visualization of the location (site time) of critical points (staves; minimum of free sites (orange), minimum coverage of $\mathrm{M} 2$ (grey), maximum coverage of DBE* (blue), minimum coverage of D1 (yellow), dominant path shift from path $B$ to $A$ (green)) throughout the microkinetic reactor overlaid with the conversion of $\mathrm{n}$-butanol (lines; right side axis; red $=513 \mathrm{~K}$, black $=523 \mathrm{~K}$, orange $=533 \mathrm{~K})$ at three temperatures $(513 \mathrm{~K}, 523 \mathrm{~K} \& 533 \mathrm{~K})$ at a $\mathrm{Si} / \mathrm{Al}=25$. 
Overall it can be concluded that the presence of di-n-butylether affects the catalyst performance in a negative way, as it results in an inhibition effect due to the highly stabilized chemisorption on the active sites of H-ZSM-5. To achieve the best results, it is important to decrease the formation of di-nbutylether as much as possible. Increasing the temperature with relatively small steps (10 K) incurs large shifts in activity, and it is thus highly recommended to perform the dehydration at temperatures above $520 \mathrm{~K}$. Generally, these simulated trends adequately predict the experimental results and thus this model can be used as a base model to implement and understand the effect of the Si/Al ratio.

\subsection{Extension of the kinetic model with effect of Si/Al ratio}

The effect of silica to alumina ratio (experimentally observed in section 3.1), which is essentially the effect of varying the adsorption strength, is captured in the model by introducing an additional parameter that modifies the adsorption enthalpy, as also used to model the cracking of alkenes across different $\mathrm{Si} / \mathrm{Al}$ ratios $[57,58,61-64]$. This parameter, $\Delta \Delta \mathrm{H}$, is defined as the modification of the adsorption enthalpy of the reactant $n$-butanol. In order to conserve the overall thermodynamic equilibrium in gas phase, the desorption steps of butenes and ether are modified with $-\Delta \Delta \mathrm{H}$. This results in an overall shift of the Gibbs energies of each intermediate and transition state with this value, meaning the thermodynamics and kinetics of the surface steps are not affected. A negative value of this parameter results in stronger adsorption caused by a more negative Gibbs energy and thus more stable adsorbed species. A visualization of this shift is available in Figure S6 of the Supporting Information. A positive value results in the opposite effect. This parameter is then used as a single parameter in the regression of the model output to the experimental data for the Si/Al ratios of 15, 40 and 140 , according to the procedure described in section 0 .

Validation of the assumptions made to construct a model describing the experimental results are shown in Figure 9 and Figure 10. These figures show the result of estimating the $\Delta \Delta \mathrm{H}$ parameter for the different $\mathrm{Si} / \mathrm{Al}$ ratios at 513K. Comparing model results across the different values for this parameter (and thus Si/Al ratio), an increase in activity is found with a more negative value of $\Delta \Delta \mathrm{H}$. This is expected as gaseous species will be more strongly stabilized at the surface resulting in higher rate of adsorption or slower desorption of formed species. As expected, no effect is observed on the overall selectivity-conversion profile in the used range: the intermediate steps are not affected and the adsorption steps are affected similarly, making the selectivity-conversion profile independent of this parameter. Figure 10 illustrates this effect clearly by the overlap for all four simulations for Si/Al of $15,25,40$ and 140 . The agreement between experimental results and model predictions confirms that the key steps controlling the selectivity are independent of the adsorption strength.

Note that $\Delta \Delta \mathrm{H}$ modifies the activity while the energetic span of the model remains unaltered (see Figure $\mathrm{S} 7$ in the supporting information) indicating that the observed activity differences related to the $\mathrm{Si} / \mathrm{Al}$ ratio cannot be captured by the simplifying assumptions inherent to the concept of energetic span [68]. The activity trend can however be related to the apparent activation energy, as this is altered with an identical value as the $\Delta \Delta \mathrm{H}$ parameter, i.e., a negative $\Delta \Delta \mathrm{H}$ value results in a decrease in apparent activation energy resulting in the increase in overall activity, since the energy of the gasphase reactants and reaction products remains unchanged but the transition state energies are shifted with $\Delta \Delta \mathrm{H}$. An indication of the effect of the $\Delta \Delta \mathrm{H}$ parameter on the Gibbs energy profile is available in Figure $\mathrm{S} 7$ of the supporting information. 


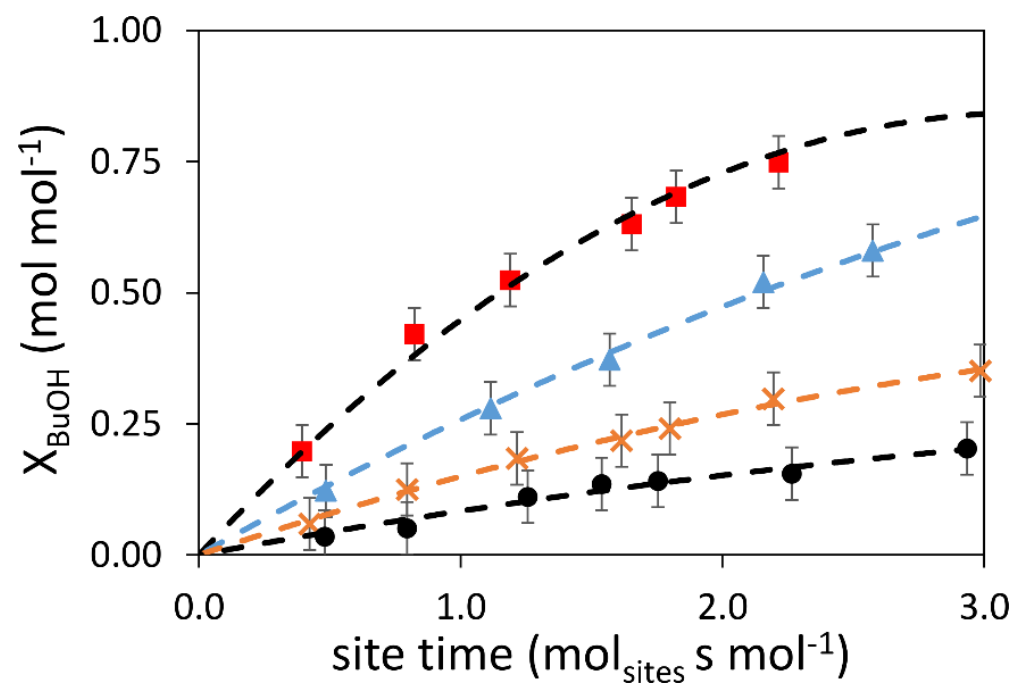

Figure 9: Conversion $\left(\mathrm{X}_{\mathrm{BuOH}}\right.$ ) as function of site time for HZSM-5 at four different Si/Al ratios: 15 (black, $\Delta \Delta \mathrm{H}=-4,8 \mathrm{~kJ} \mathrm{~mol}^{-1}$ ), 25 (orange, $\Delta \Delta \mathrm{H}=0 \mathrm{~kJ} \mathrm{~mol}^{-1}$ ), 40 (blue, $\Delta \Delta \mathrm{H}=5.3 \mathrm{~kJ} \mathrm{~mol}^{-1}$ ) and 140 (red, $\Delta \Delta \mathrm{H}=11.3 \mathrm{~kJ} \mathrm{~mol}^{-1}$ ) at $513 \mathrm{~K}$ and $\mathrm{p}_{\text {BuOH }}=29 \mathrm{kPa}$. Lines represent model simulated values. Error bars represent the $95 \%$ confidence interval.

These results are indicative of a strong effect of Si/Al ratio related to the adsorption strength of reactants and products. As seen in section 2.1 in Table 1, the adsorption strength strongly decreased with an increased Si/Al ratio, which is also necessary to achieve a good fit of model predictions with the experimental results.

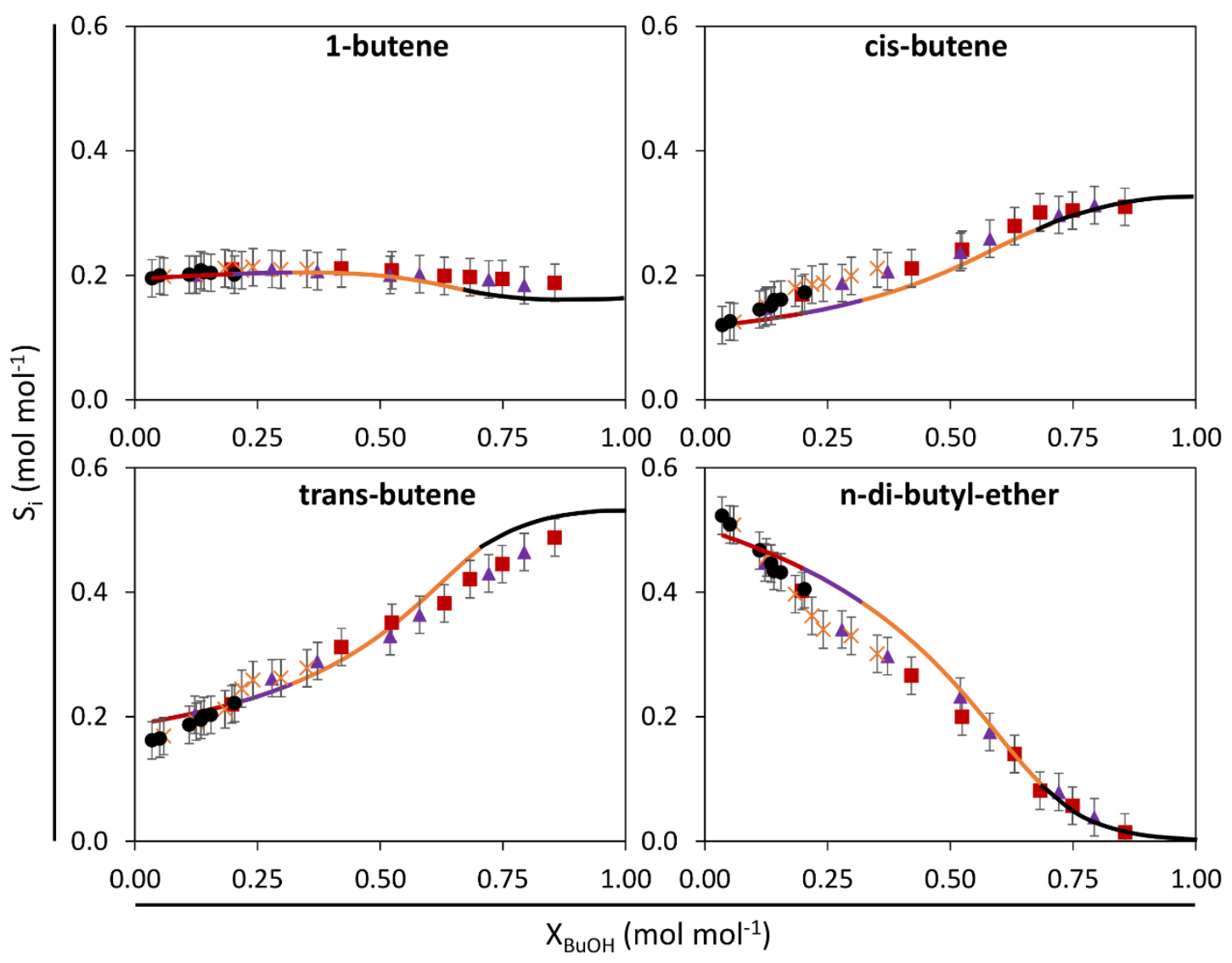

Figure 10: Selectivity $\left(\mathrm{S}_{\mathrm{i}}\right)$ of the different reaction products (1-butene, cis-2-butene, trans-2-butene and di-n-butylether) as a function of conversion $\left(\mathrm{X}_{\mathrm{BuOH}}\right.$ ) at four different Si/Al ratios: 15 (black, $\Delta \Delta \mathrm{H}=-4,8 \mathrm{~kJ} / \mathrm{mol}$ ), 25 (orange, $\Delta \Delta \mathrm{H}=0 \mathrm{~kJ} / \mathrm{mol}$ ), 40 (blue, $\Delta \Delta \mathrm{H}=5.3 \mathrm{~kJ} / \mathrm{mol}$ ) and 140 (red, $\Delta \Delta \mathrm{H}=11.3 \mathrm{~kJ} / \mathrm{mol})$. Lines represent model simulated results. $\left(513 \mathrm{~K} ; \mathrm{p}^{0} \mathrm{BuOH}=29 \mathrm{kPa}\right)$. Error bars represent the $95 \%$ confidence interval. 
Indirectly this approach indicates a non-saturated surface (for a Si/Al ratio of 25), as it is possible to adsorb more molecules by increasing the adsorption strength to achieve a good fit at a Si/Al ratio of 15. As for the higher $\mathrm{Si} / \mathrm{Al}$ ratios ( 40 and 140 ) the overall surface coverage is decreased due to the positive value of $\Delta \Delta \mathrm{H}$, as is illustrated by the surface coverages shown in Table 4 which represent the surface coverages of the dominant species for each model simulation at the initial conditions, i.e., at a zero conversion.

It is clearly visible that decreasing the adsorption strength of $n$-butanol, represented by an increasing value of $\Delta \Delta \mathrm{H}$, leads to a decrease in the coverage of all surface species (Table S3). This decrease is for each component proportionally the same and is the most clearly visible for the dominant species: M1, D1 and DBE* (Table 4). When decreasing the adsorption enthalpy (less negative), which corresponds to increasing the Si/Al ratio, the total coverage (derived from equation (7)) , 1 minus the number of free active sites $\left(\theta^{*}\right)$ is decreased as the number of free sites increases starting at 1.000 to $0.999,0.997$ and 0.990 for respectively a Si/Al of 15, 25, 40 and 140. This shows that overall less species are present at the active sites, resulting in an overall decrease of activity. Also, as the coverage of each species is decreased proportionally for each $\mathrm{Si} / \mathrm{Al}$ ratio, an equal proportional shift of all reaction rates occurs, resulting in the identical selectivity-conversion relation for each Si/Al ratio as shown in Figure 10.

Table 4: Estimated values of $\Delta \Delta \mathrm{H}$ (with $95 \%$ confidence intervals) and model simulated initial surface coverages, i.e., at $\mathrm{X}_{\mathrm{BuOH}}=0$, of the dominant species at the four different values of $\Delta \Delta \mathrm{H}\left(\mathrm{kJ} \mathrm{mol}^{-1}\right)$, related to four different Si/Al ratios $(15,25$, 40 and 140 ) at $\mathrm{T}=513 \mathrm{~K}, \mathrm{p}^{0}{ }_{\text {BuOH }}=29 \mathrm{kPa}$.

\begin{tabular}{lccccc}
\hline \multirow{2}{*}{ Surface species } & \multicolumn{5}{c}{ Coverages } \\
\cline { 2 - 6 } & $\Delta \Delta H: A:$ & $-4.8 \pm 2.3$ & 0.0 & $5.3 \pm 3.1$ & $11.3 \pm 2.6$ \\
\hline Free Sites & & $3.12 \mathrm{E}-07$ & $1.57 \mathrm{E}-05$ & $3.08 \mathrm{E}-03$ & $1.05 \mathrm{E}-02$ \\
M1 & $2.13 \mathrm{E}-03$ & $2.13 \mathrm{E}-03$ & $2.12 \mathrm{E}-03$ & $2.10 \mathrm{E}-03$ \\
D1 & & $9.98 \mathrm{E}-01$ & $9.98 \mathrm{E}-01$ & $9.94 \mathrm{E}-01$ & $9.87 \mathrm{E}-01$ \\
DBE* & & $3.26 \mathrm{E}-04$ & $3.26 \mathrm{E}-04$ & $3.25 \mathrm{E}-04$ & $3.22 \mathrm{E}-04$ \\
\hline
\end{tabular}

Overall it can be concluded that the introduction of this $\Delta \Delta \mathrm{H}$ parameter into the model allows to accurately capture the effect of the Si/Al ratio on the dehydration of $n$-butanol towards butenes.

\section{$4 \quad$ Conclusions}

Dehydration of butanol towards butenes over different zeolite catalysts can be utilized as an alternative drop-in approach towards classic refineries, were the obtained butenes can be used as a green feedstock for a range of products.

Experimental investigation of the effect of $\mathrm{Si} / \mathrm{Al}$ ratio within HZSM-5 showed a decrease in activity of the catalyst per active site with increasing Si/Al ratio, without affecting the selectivity profile. The average adsorption strength of $\mathrm{NH}_{3}$ on the catalytic sites indicated that the increase in $\mathrm{Si} / \mathrm{Al}$ ratio results in weaker adsorption on acid sites.

To understand the underlying effects, a microkinetic model was constructed at a Si/Al ratio of 25 based on literature DFT calculations. This model was further optimized by linear regression of seven key reaction rates to experimental data at four different temperatures. The necessary modifications were mainly correlated to the activation energies of the transition state of the identified reaction steps, with a neglect able change in pre-exponential factors. This resulted in an adequate model for the dehydration of butanol across the tested temperature range of $503 \mathrm{~K}$ to $533 \mathrm{~K}$. 
In this model, the effect of $\mathrm{Si} / \mathrm{Al}$ ratio was modeled using an additional $\Delta \Delta \mathrm{H}$ parameter, in a similar fashion to modeling on alkene cracking, which modifies the adsorption strength of the intermediates in the model. With this parameter, a good agreement for all Si/Al ratios was found by varying the value between -4.8 to $+11.3 \mathrm{~kJ} / \mathrm{mol}$ in the range of $\mathrm{Si} / \mathrm{Al}$ from 15 towards 140 , which corresponds to stronger adsorption at low and weaker adsorption at high Si/Al ratios. With these variations in $\Delta \Delta \mathrm{H}$, it was found that the catalyst surface is not fully saturated and hence, an increase in adsorption strength resulted in an overall higher surface coverage. With this increase in overall coverage, the distribution of surface species stayed unaffected, resulting in a shift in activity without affecting selectivity-conversion profiles, which is in agreement with the obtained experimental results.

\section{$5 \quad$ Acknowledgments}

The calculations were carried out using the STEVIN Supercomputer Infrastructure at Ghent University, funded by Ghent University, the Flemish Supercomputer Center (VSC), the Hercules Foundation, and the Flemish Government (department EWI). 
[1] R. Luque, L. Herrero-Davila, J.M. Campelo, J.H. Clark, J.M. Hidalgo, D. Luna, J.M. Marinas, A.A. Romero, Biofuels: a technological perspective, Energ Environ Sci, 1 (2008) 542-564.

[2] M. Mascal, E.B. Nikitin, Direct, high-yield conversion of cellulose into biofuel, Angew Chem Int Edit, 47 (2008) 7924-7926.

[3] J.F. Haw, W.G. Song, D.M. Marcus, J.B. Nicholas, The mechanism of methanol to hydrocarbon catalysis, Accounts Chem Res, 36 (2003) 317-326.

[4] J. Sun, Y. Wang, Recent Advances in Catalytic Conversion of Ethanol to Chemicals, Acs Catal, 4 (2014) 1078-1090.

[5] A.J. Ragauskas, C.K. Williams, B.H. Davison, G. Britovsek, J. Cairney, C.A. Eckert, W.J. Frederick, J.P. Hallett, D.J. Leak, C.L. Liotta, J.R. Mielenz, R. Murphy, R. Templer, T. Tschaplinski, The path forward for biofuels and biomaterials, Science, 311 (2006) 484489.

[6] M.J. Taherzadeh, K. Karimi, Enzyme-Based Hydrolysis Processes for Ethanol from Lignocellulosic Materials: A Review, Bioresources, 2 (2007) 707-738.

[7] M.J. Taherzadeh, K. Karimi, Acid-Based Hydrolysis Processes for Ethanol from Lignocellulosic Materials: A Review, Bioresources, 2 (2007) 472-499.

[8] E. Palmqvist, B. Hahn-Hagerdal, Fermentation of lignocellulosic hydrolysates. II: inhibitors and mechanisms of inhibition, Bioresource Technol, 74 (2000) 25-33.

[9] E. Palmqvist, B. Hahn-Hagerdal, Fermentation of lignocellulosic hydrolysates. I: inhibition and detoxification, Bioresource Technol, 74 (2000) 17-24.

[10] J. Swana, Y. Yang, M. Behnam, R. Thompson, An analysis of net energy production and feedstock availability for biobutanol and bioethanol, Bioresource Technol, 102 (2011) 2112-2117.

[11] N. Savage, The ideal biofuel, Nature, 474 (2011) S9-S11.

[12] C. Jin, M.F. Yao, H.F. Liu, C.F.F. Lee, J. Ji, Progress in the production and application of n-butanol as a biofuel, Renew Sust Energ Rev, 15 (2011) 4080-4106.

[13] A.G. Gayubo, A.T. Aguayo, A. Atutxa, R. Aguado, J. Bilbao, Transformation of oxygenate components of biomass pyrolysis oil on a HZSM-5 zeolite. I. Alcohols and phenols, Ind Eng Chem Res, 43 (2004) 2610-2618.

[14] D.T. Jones, D.R. Woods, Acetone-Butanol Fermentation Revisited, Microbiol Rev, 50 (1986) 484-524.

[15] N. Qureshi, T.C. Ezeji, Butanol, 'a superior biofuel' production from agricultural residues (renewable biomass): recent progress in technology, Biofuel Bioprod Bior, 2 (2008) 319-330.

[16] Y. Ni, Z.H. Sun, Recent progress on industrial fermentative production of acetonebutanol-ethanol by Clostridium acetobutylicum in China, Appl Microbiol Biot, 83 (2009) 415-423.

[17] C.L. Cheng, P.Y. Che, B.Y. Chen, W.J. Lee, C.Y. Lin, J.S. Chang, Biobutanol production from agricultural waste by an acclimated mixed bacterial microflora, Appl Energ, 100 (2012) 3-9.

[18] C.L. Cheng, P.Y. Che, B.Y. Chen, W.J. Lee, L.J. Chien, J.S. Chang, High yield bio-butanol production by solvent-producing bacterial microflora, Bioresource Technol, 113 (2012) 58-64. 
[19] C. Williams, M.A. Makarova, L.V. Malysheva, E.A. Paukshtis, K.I. Zamaraev, J.M. Thomas, Mechanistic Studies of the Catalytic Dehydration of Isobutyl Alcohol on NahZsm-5, J Chem Soc Faraday T, 86 (1990) 3473-3485.

[20] M.A. Makarova, C. Williams, V.N. Romannikov, K.I. Zamaraev, J.M. Thomas, Influence of Pore Confinement on the Catalytic Dehydration of Isobutyl Alcohol on H-Zsm-5, J Chem Soc Faraday T, 86 (1990) 581-584.

[21] M.A. Makarova, E.A. Paukshtis, J.M. Thomas, C. Williams, K.I. Zamaraev, Dehydration of N-Butanol on Zeolite H-Zsm-5 and Amorphous Aluminosilicate - Detailed Mechanistic Study and the Effect of Pore Confinement, J Catal, 149 (1994) 36-51.

[22] D.Z. Zhang, R. Al-Hajri, S.A.I. Barri, D. Chadwick, One-step dehydration and isomerisation of $\mathrm{n}$-butanol to iso-butene over zeolite catalysts, Chem Commun, 46 (2010) 4088-4090.

[23] J.H. Kwak, R. Rousseau, D.H. Mei, C.H.F. Peden, J. Szanyi, The Origin of Regioselectivity in 2-Butanol Dehydration on Solid Acid Catalysts, Chemcatchem, 3 (2011) 1557-1561.

[24] S. Jeong, H. Kim, J.H. Bae, D.H. Kim, C.H.F. Peden, Y.K. Park, J.K. Jeon, Synthesis of butenes through 2-butanol dehydration over mesoporous materials produced from ferrierite, Catal Today, 185 (2012) 191-197.

[25] S. Liu, G. Liu, Z. Liu, X. Sun, Butene-2 Oligomerization to Heavy Olefins over ZSM-5 Zeolite, Petrol Sci Technol, 27 (2009) 1653-1660.

[26] A. Coelho, G. Caeiro, M.A.N.D.A. Lemos, F. Lemos, F.R. Ribeiro, 1-Butene oligomerization over ZSM-5 zeolite: Part 1-Effect of reaction conditions, Fuel, 111 (2013) 449-460.

[27] A.M. Varvarin, K.M. Khomenko, V.V. Brei, Conversion of n-butanol to hydrocarbons over H-ZSM-5, H-ZSM-11, H-L and H-Y zeolites, Fuel, 106 (2013) 617-620.

[28] E.G. Derouane, J.B. Nagy, P. Dejaifve, J.H.C. Vanhooff, B.P. Spekman, J.C. Vedrine, C. Naccache, Elucidation of Mechanism of Conversion of Methanol and Ethanol to Hydrocarbons on a New Type of Synthetic Zeolite, J Catal, 53 (1978) 40-55.

[29] X.W. Guo, H.Y. Long, Y. Zhao, X.J. Cheng, L.P. Sun, J.D. Bi, X.S. Wang, Synthesis of nanoscale HZSM-5 zeolite and its application in alkylation, dehydration of bio-ethanol and upgrading of FCC gasoline, Abstr Pap Am Chem S, 240 (2010).

[30] K. Van der Borght, V.V. Galvita, G.B. Marin, Ethanol to higher hydrocarbons over Ni, Ga, Fe-modified ZSM-5: Effect of metal content, Appl Catal a-Gen, 492 (2015) 117126.

[31] K. Van der Borght, R. Batchu, V.V. Galvita, K. Alexopoulos, M.F. Reyniers, J.W. Thybaut, G.B. Marin, Insights into the Reaction Mechanism of Ethanol Conversion into Hydrocarbons on H-ZSM-5, Angew Chem Int Edit, 55 (2016) 12817-12821.

[32] M. John, K. Alexopoulos, M.F. Reyniers, G.B. Marin, First-Principles Kinetic Study on the Effect of the Zeolite Framework on 1-Butanol Dehydration, Acs Catal, 6 (2016) 4081-4094.

[33] Y.T. Kim, J.P. Chada, Z.R. Xu, Y.J. Pagan-Torres, D.C. Rosenfeld, W.L. Winniford, E. Schmidt, G.W. Huber, Low-temperature oligomerization of 1-butene with H-ferrierite, J Catal, 323 (2015) 33-44.

[34] M. John, K. Alexopoulos, M.F. Reyniers, G.B. Marin, Reaction path analysis for 1butanol dehydration in H-ZSM-5 zeolite: Ab initio and microkinetic modeling, J Catal, 330 (2015) 28-45. 
[35] M. John, K. Alexopoulos, M.F. Reyniers, G.B. Marin, Mechanistic insights into the formation of butene isomers from 1-butanol in H-ZSM-5: DFT based microkinetic modelling, Catal Sci Technol, 7 (2017) 1055-1072.

[36] D. Gunst, K. Alexopoulos, K. Van der Borght, M. John, V. Galvita, M.F. Reyniers, A. Verberckmoes, Study of butanol conversion to butenes over H-ZSM-5: Effect of chemical structure on activity, selectivity and reaction pathways, Appl Catal a-Gen, 539 (2017) 1-12.

[37] N. Wang, M.H. Zhang, Y.Z. Yu, Distribution of aluminum and its influence on the acid strength of Y zeolite, Micropor Mesopor Mat, 169 (2013) 47-53.

[38] S.M. Opalka, T.L. Zhu, Influence of the Si/Al ratio and Al distribution on the H-ZSM-5 lattice and Bronsted acid site characteristics, Micropor Mesopor Mat, 222 (2016) 256270.

[39] Y. Furumoto, Y. Harada, N. Tsunoji, A. Takahashi, T. Fujitani, Y. Ide, M. Sadakane, T. Sano, Effect of acidity of ZSM-5 zeolite on conversion of ethanol to propylene, Appl Catal a-Gen, 399 (2011) 262-267.

[40] M.J. Rice, A.K. Chakraborty, A.T. Bell, Al next nearest neighbor, ring occupation, and proximity statistics in ZSM-5, J Catal, 186 (1999) 222-227.

[41] I. Craciun, M.F. Reyniers, G.B. Marin, Effects of acid properties of Y zeolites on the liquid-phase alkylation of benzene with 1-octene: A reaction path analysis, J Mol Catal a-Chem, 277 (2007) 1-14.

[42] J.W. Ward, Nature of Active Sites on Zeolites .11. Effects of Silica-to-Alumina Ratio on Acidity and Catalytic Activity of Synthetic Faujasite-Type Zeolites, J Catal, 17 (1970) 355-\&.

[43] A.F.P. Ferreira, M.C. Mittelmeijer-Hazeleger, A. Bliek, J.A. Moulijn, Influence of Si/Al ratio on hexane isomers adsorption equilibria, Micropor Mesopor Mat, 111 (2008) 171-177.

[44] V.C.S. Palla, D. Shee, S.K. Maity, Conversion of $n$-butanol to gasoline range hydrocarbons, butylenes and aromatics, Appl Catal a-Gen, 526 (2016) 28-36.

[45] A.K. Talukdar, K.G. Bhattacharyya, S. Sivasanker, HZSM-5 catalysed conversion of aqueous ethanol to hydrocarbons, Appl Catal a-Gen, 148 (1997) 357-371.

[46] A.F.P. Ferreira, M.C. Mittelmeijer-Hazeleger, J.V.D. Bergh, S. Aguado, J.C. Jansen, G. Rothenberg, A.E. Rodrigues, F. Kapteijn, Adsorption of hexane isomers on MFI type zeolites at ambient temperature: Understanding the aluminium content effect, Micropor Mesopor Mat, 170 (2013) 26-35.

[47] R.C. Wei, C.Y. Li, C.H. Yang, H.H. Shan, Effects of ammonium exchange and Si/Al ratio on the conversion of methanol to propylene over a novel and large partical size ZSM5, J Nat Gas Chem, 20 (2011) 261-265.

[48] A.S. Al-Dughaither, H. de Lasa, HZSM-5 Zeolites with Different SiO2/Al2O3 Ratios. Characterization and NH3 Desorption Kinetics, Ind Eng Chem Res, 53 (2014) 1530315316.

[49] B.C. Knott, C.T. Nimlos, D.J. Robichaud, M.R. Nimlos, S. Kim, R. Gounder, Consideration of the Aluminum Distribution in Zeolites in Theoretical and Experimental Catalysis Research, Acs Catal, 8 (2018) 770-784.

[50] T.K. Phung, L.P. Hernandez, A. Lagazzo, G. Busca, Dehydration of ethanol over zeolites, silica alumina and alumina: Lewis acidity, Bronsted acidity and confinement effects, Appl Catal a-Gen, 493 (2015) 77-89. 
[51] K. Van der Borght, K. Toch, V.V. Galvita, J.W. Thybaut, G.B. Marin, Information-Driven Catalyst Design Based on High-Throughput Intrinsic Kinetics, Catalysts, 5 (2015) 19481968.

[52] R.J. Berger, E.H. Stitt, G.B. Marin, F. Kapteijn, J.A. Moulijn, Eurokin - Chemical reaction kinetics in practice, Cattech, 5 (2001) 30-60.

[53] J.P. Perdew, K. Burke, M. Ernzerhof, Generalized gradient approximation made simple, Phys Rev Lett, 77 (1996) 3865-3868.

[54] S. Grimme, Semiempirical GGA-type density functional constructed with a long-range dispersion correction, J Comput Chem, 27 (2006) 1787-1799.

[55] C. Stegelmann, A. Andreasen, C.T. Campbell, Degree of Rate Control: How Much the Energies of Intermediates and Transition States Control Rates, J Am Chem Soc, 131 (2009) 8077-8082.

[56] T.A. Semelsberger, K.C. Ott, R.L. Borup, H.L. Greene, Role of acidity on the hydrolysis of dimethyl ether (DME) to methanol, Appl Catal B-Environ, 61 (2005) 281-287.

[57] R. Van Borm, A. Aerts, M.F. Reyniers, J.A. Martens, G.B. Marin, Catalytic Cracking of 2,2,4-Trimethylpentane on FAU, MFI, and Bimodal Porous Materials: Influence of Acid Properties and Pore Topology, Ind Eng Chem Res, 49 (2010) 6815-6823.

[58] R. Van Borm, M.F. Reyniers, J.A. Martens, G.B. Marin, Catalytic Cracking of Methylcyclohexane on FAU, MFI, and Bimodal Porous Materials: Influence of Acid Properties and Pore Topology, Ind Eng Chem Res, 49 (2010) 10486-10495.

[59] J.A. Dumesic, The Microkinetics of heterogeneous catalysis, American Chemical Society1993.

[60] M.F. Reyniers, G.B. Marin, Experimental and Theoretical Methods in Kinetic Studies of Heterogeneously Catalyzed Reactions, Annu Rev Chem Biomol, 5 (2014) 563-+.

[61] G.G. Martens, G.B. Marin, J.A. Martens, P.A. Jacobs, G.V. Baroni, A fundamental kinetic model for hydrocracking of C-8 to C-12 alkanes on Pt/US-Y zeolites, Journal of Catalysis, 195 (2000) 253-267.

[62] J.W. Thybaut, G.B. Marin, G.V. Baron, P.A. Jacobs, J.A. Martens, Alkene protonation enthalpy determination from fundamental kinetic modeling of alkane hydroconversion on Pt/H-(US)Y-zeolite, J Catal, 202 (2001) 324-339.

[63] G. Yaluris, R.J. Madon, J.A. Dumesic, Catalytic ramifications of steam deactivation of $Y$ zeolites: An analysis using 2-methylhexane cracking, J Catal, 186 (1999) 134-146.

[64] G. Yaluris, J.E. Rekoske, L.M. Aparicio, R.J. Madon, J.A. Dumesic, Isobutane Cracking over Y-Zeolites .1. Development of a Kinetic-Model, J Catal, 153 (1995) 54-64.

[65] R. Van Borm, M.F. Reyniers, G.B. Marin, Catalytic cracking of alkanes on FAU: Singleevent microkinetic modeling including acidity descriptors, Aiche Journal, 58 (2012) 2202-2215.

[66] I. Craciun, M.F. Reyniers, G.B. Marin, Liquid-phase alkylation of benzene with octenes over Y zeolites: Kinetic modeling including acidity descriptors, J Catal, 294 (2012) 136150.

[67] B.A. Watson, M.T. Klein, R.H. Harding, Mechanistic modeling of $n$-heptane cracking on HZSM-5, Ind Eng Chem Res, 35 (1996) 1506-1516.

[68] S. Kozuch, S. Shaik, How to Conceptualize Catalytic Cycles? The Energetic Span Model, Accounts Chem Res, 44 (2011) 101-110. 